\title{
RE-EVALUATING THE POMPEII AULOI
}

\begin{abstract}
The four best-preserved aulos pipes unearthed at Pompeii are examined and their original pitches are as far as possible determined by mathematical analysis. It is argued that the scales of the instruments as well as specific details of their mechanism fit well with our knowledge of music from the Roman Imperial period.
\end{abstract}

The pairs of reed pipes called aulós by the Greeks and tibia in Latin were the dominant wind instrument of Classical antiquity. ${ }^{1}$ Much of theatre, concert hall and everyday music was performed or accompanied by these 'flutes', as they are still most often translated, misleading though this is nowadays. ${ }^{2}$ The recreation of the aulos, as far as is possible, has therefore been a dream of many interested in the sound of the ancient world. Necessarily, such a recreation not only concerns playing technique and timbre, but also involves the question of available scales. Here the written sources give us little information. If they are concerned with the relation of tonal structures to instruments at all, they address the lyre. ${ }^{3}$ Thus one must turn to the remains of actual auloi, of which quite a number have been unearthed. ${ }^{4}$ The determination of their scales is generally problematic, however, because of the fragmentary state of most extant artefacts. Even where the upper part of the instrument is not missing, in the absence of the reed mouthpieces the effective length of the vibrating air column can be inferred only indirectly. One has to calculate the pitches sounded by the individual finger holes for all possible extensions, to find which one gives a plausible scale - a scale, that is, which can be related to the systems of ancient harmonic theory and/or to extant ancient melodies. If the instrument is broken at the upper end, as is usually the case, the procedure is not in principle different from the case where only the reed is missing. But since together with the extension of the reed, the length of the missing part of the tube has to be estimated, the range in which the unknown parameter is to be sought is much larger, and the results are therefore less certain. On top of this, in most cases only one pipe of a pair has survived, so that we cannot even hope for the 'scale' of an entire instrument.

One exception is the Louvre aulos, a pair of complete pipes of unknown date and provenance, probably from Egypt. In a previous study I have analysed this instrument, and determined its scale. $^{5}$ Elsewhere I have shown how this type of aulos can be related to the evolution of ancient theory, and especially to the conception of the so-called 'Perfect System', the two-octave scale which underlies the description of tonal space from the fourth century BC on. ${ }^{6}$

On an instrument with two separate pipes only five finger holes per pipe can be played at once. Accordingly the 'primitive' Greek aulos had five finger holes. The Louvre pipes, although otherwise of simple make, have considerably more. Conceivably, on such instruments the holes not needed for a given piece were stopped with wax or wooden plugs. ${ }^{7}$ Such restrictions were overcome by the invention of metal collars, probably in the late fifth century BC. A bone or ivory core was covered in two layers of thin bronze or silver; around the inner, which was glued to the core,

\footnotetext{
${ }^{1}$ On the aulos in general, $c f$. Howard (1893); Becker (1966) (less recommended); West (1992) 81-107 (also discusses the more important fragments from the Greek world); Landels (1999) 24-46. Especially on the history of the aulos, Barker (2002) 13-81.

2 In former times, English 'flute' (like German 'Flöte', etc.) encompassed what is now called, more technically, woodwind.

${ }^{3}$ Greek harmonic theory proper is concerned with the description of an abstract tonal space. The selection of notes and their employment within a composition belonged to the realm of specifically 'musical' expertise ( $c f$. e.g. Aristox. Harm. 1.1f, p.5.4-6.5 Da Rios; ps.-Plut. Mus.
}

1142e-1143d); only faint echoes of corresponding works have survived (e.g. Aristid. Quint. 1.12; ps.-Plut. Mus. 1137a-d).

${ }^{4}$ For an overview of Greek aulos fragments of the early type (which does not concern us here), see Psaroudakês (2002). For an important, if rather pessimistic, discussion of the problems involved in reconstruction, see Landels (1981).

${ }^{5}$ Hagel (2004).

${ }^{6}$ Hagel (2005).

${ }^{7}$ In Hagel (2004) 385 n.81, the rather unlikely possibility is considered that the instrument was meant to be equipped with a mechanism, but not finished. 
the outer revolved in several separate bands, manipulated by tiny knobs soldered to their surface. ${ }^{8}$ Thus it became possible to close and open individual finger holes during performance, and consequently to modulate between different scales, and to extend the ambitus by changing the playing position of the hand. ${ }^{9}$

The present study focuses on the best-preserved auloi of this expensive professional type. Four complete pipes of this kind were excavated at Pompeii in $1867 .{ }^{10}$ They consist of metal-clad ivory tubes of different length, but similar inner and outer diameter, terminating in bulbs and reed inserts of similar shape. The number of finger holes varies from ten to fifteen. Unfortunately part of the outer metallic layer is considerably corroded. Nevertheless A. Howard, who was the first to submit the instruments to careful study, concluded that originally all holes were equipped with rotating collars. ${ }^{11}$ In general, every single hole was provided a band of its own and could thus be opened and closed individually.

In former studies, attempts at determining the scales of the Pompeii instruments have been made experimentally as well as by means of calculation, with diverging results. ${ }^{12}$ In the following, their design will be examined by more sophisticated mathematical means; the results will be embedded in the context of ancient music.

Measurements of the pipes and finger holes are given by Howard. However, a comparison of his figures with the hole positions discernible in the photographs that accompany his study ${ }^{13}$ reveals a certain amount of incongruity, especially concerning pipes 2 and 3. ${ }^{14}$ FIG. 1 makes the differences obvious by superimposing Howard's figures, transformed into computer graphics, over his photographs. The visible distribution of finger holes is evidently at odds with Howard's measurements (FIG. 1).

On closer inspection it becomes clear that the lack of congruence cannot be rectified by applying a different scale, nor can it in most cases be explained by optical effects. It is true that at least part of the major problem with Pipe 2, where the two lowest holes are much further away from the rest on the photograph than they should be according to the measurements, could plausibly be explained by photographic tilt distortion, assuming that the broken lower section was in fact tilted mainly towards the camera. But where properly aligned measurements alternate with displaced ones, no similar explanation is feasible (note also that the distance between the lowest holes on Pipe 2 itself is too small on the photograph, which runs contrary to the tilt distortion hypothesis).

It was therefore necessary to obtain corrected values where possible. Since I have not yet been able to examine the originals, this has been done from photographs. The Naples National Museum

\footnotetext{
${ }^{8}$ For this mechanism, $c f$. Howard (1893) 5-8; Bodley (1946) (whose scales are unfortunately based on the unfounded theory proposed by Schlesinger (1939); cf. Landels (1981) 300-1); Masaraki (1974); Litvinsky (1999). On a different slider mechanism, $c f$. also Byrne (2002). In most cases only scattered sections of these elaborate pipes remain, which could not be assembled into instruments (Masaraki's reconstruction of a single pipe is based on principles which she has not made clear; it probably contains parts of more than one tube).

${ }^{9}$ I have confirmed these possibilities on experimental reconstructions made of plastic (a reproduction of the highly developed metalwork of the ancient instruments seamless tubes with walls of about $0.1-0.2 \mathrm{~mm}$ thickness, air-tight, when fitted over each other - exceeds my current resources).

${ }^{10}$ Naples Museum Cat. 76891-4, hereafter referred to as pipes 1-4.
}

\footnotetext{
${ }^{11}$ Howard (1893) 47-51; esp. 50-1. Note that this is in fact an almost necessary assumption, since the absence of collars on some of the holes would render the system useless: low holes cannot be played unless all higher holes are closed by the mechanism. Thus, only the lowest four holes could possibly lack a collar; but if the fundamental of the pipe ought to be accessible together with some higher notes, these lowest notes must be closable as well.

${ }^{12}$ Experiment: possibly Gevaert (1881) 295-6; 645-7 (rightly criticized by Howard (1893) 55 n.1); Howard (1893) 51-5; Curtis (1914) 102 (whose figures, purportedly based on Howard, are flawed: he seems to replace hole 2 from the lower end with two new holes, omitting hole 7 instead; the other measurements are off by up to 13mm). Calculation: Letters (1969) (based on Howard's measurements).

${ }^{13}$ Howard (1893) pl. 2.

14 The discrepancies might be partly due to systematic errors in Howard's procedure of measurement; but one can only speculate.
} 
Pipe 2

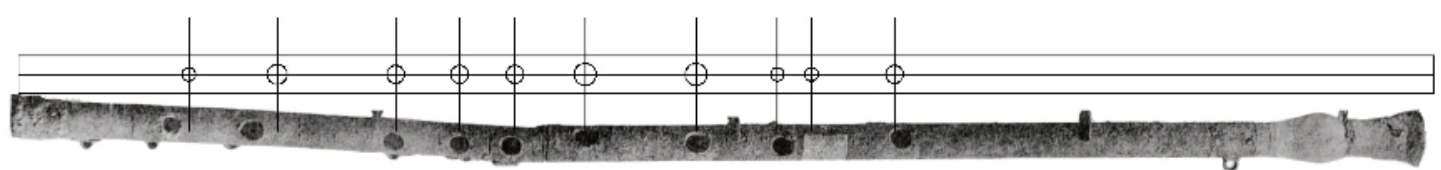

Pipe 3

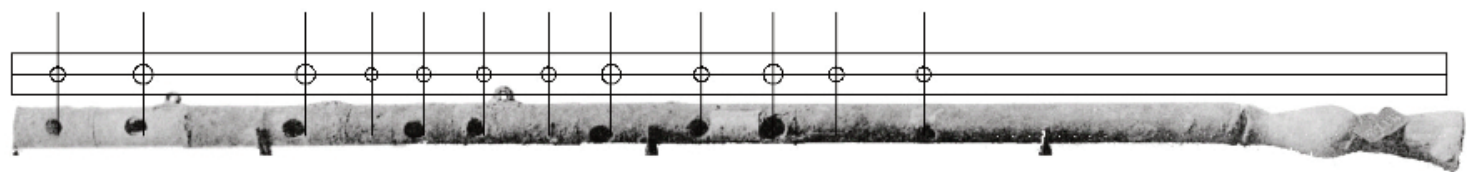

FIG. 1. Comparing Howard's measurements and photograph

kindly provided sets of excellent images, which allowed detailed measurements. ${ }^{15}$ However, since the pipes have meanwhile disintegrated into several parts, presumably during the very process of cleaning that allowed access to details formerly hidden, the old photographs are still an indispensable source for the original alignment of the sections. For a few sections that appear to be lost they are in fact the only source of information. Here, too, the modern images can at least contribute the scale; for problems of detail Howard's photographs can be crosschecked with others published by F. Behn. ${ }^{16}$ The comparison is greatly aided by the fact that the boundaries between the turning bands provide unmistakable points of reference, visible also in the low-quality images in Behn's book. To obtain as exact measurements as possible, I have made extensive use of graphics software: bringing all available images to scale, aligning them with a view to the old photographs as well as, where feasible, to the edges of the pieces now broken, then drawing vertical lines through the centres of the finger holes and finally having the distances between these evaluated by the computer. In a last step I created a schematic representation of the resulting data, ${ }^{17}$ which were once more compared with the images. Plates $1(a, b)$ and $2(a, b)$ may give a rough impression of this process; they by no means reflect it in its entirety. A schematic representation of the results, including some finger holes not detected by Howard, is presented in FIG. 2 (on the reed extensions, see below).

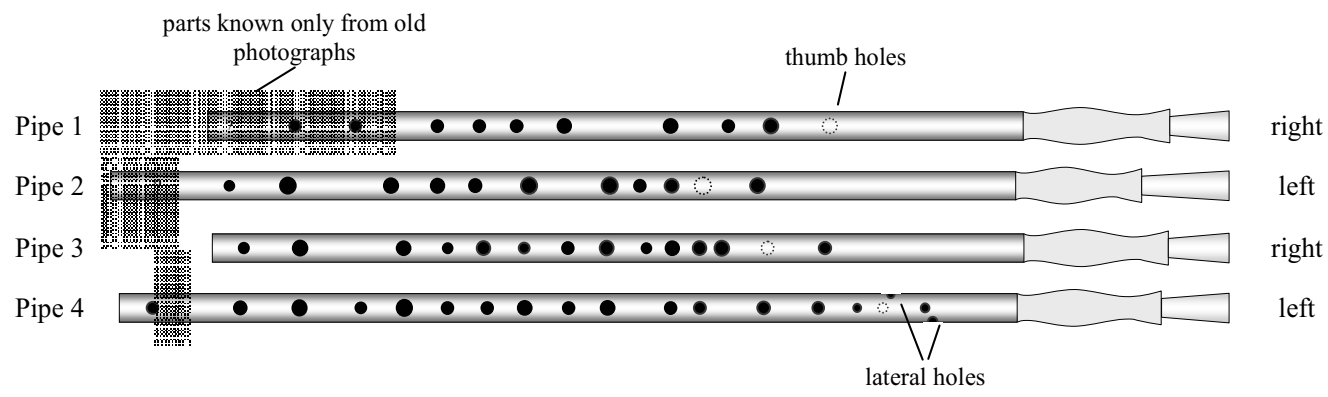

FIG. 2. Schematic representations of measurements

${ }^{15}$ I want to express my gratitude to Dr. Maria Nava, Soprintendente per i Beni Archeologici di Napoli e Caserta, and her team.
${ }^{16}$ Behn (1954) Taf. 58 Abb. 131. On this plate the contours of the light-coloured ivory bulbs are retouched.

${ }^{17}$ This was done with an extension of my aulos software described in Hagel (2004). 
Some words on the single pipes are in place. The lower part of Pipe 1 does not appear on any recent photograph. A hole close to the end (similar to that in Pipe 3), not detected by Howard, is presumed by F.A. Gevaert. ${ }^{18}$ This pipe stands out in the position of its thumb-hole, which is second to top on all other extant Greek auloi of all periods. ${ }^{19}$ Howard's figures seem reasonably accurate.

The lower end of Pipe 2 seems also missing now, which is especially frustrating because this deprives us of the chance of definitely excluding the presence of another hole near the end. Such a hole must be suspected, based on the fact that the next higher band has no hole, but one of the knobs by which the turning bands are operated; this would make sense if the bands were connected so that the hypothetical remote hole was more easily accessed by a less remote handle. As regards the proportions of the pipe, Howard's photograph emerges as more reliable than his measurements, with only a minimal amount of tilt distortion; in contrast, the lower part of Behn's photograph is obviously contracted by this geometric effect. In addition to Howard's finger holes, there are clear traces of another one, fourth from the top ( $c f$. PLATE 3(a)). It was apparently operated by the same metal collar as its neighbour above. ${ }^{20}$

On Pipe 3, two finger holes are discernible in addition to Howard's twelve (Plates 3(b)-(c)), both operated together with their upper neighbours.

Of Pipe 4 a short bit close to the end is missing. Unfortunately this part contained a hole about which Howard's accounts are contradictory, as we shall see below. The eleventh hole from the lower end is located high within its band, not centrally, as Howard believed (PLATE 3(d)). Of another hole low in this band, which one might expect by analogy with Pipes 2 and 3, I could find no traces. The pipe is broken at the height of hole 12. In Howard's photograph the two parts are in fact separated by an (invisible) gap of about 3mm; but when he took his measurements, the gap must have been reduced to almost nothing. Above the entire row of Howard's holes, the cleaned pipe revealed a thumb hole, ${ }^{21}$ a higher hole for the index finger, and at short distances above each of these respectively, two lateral holes. Whether all of these were really finger holes, and how their bands worked, seems almost impossible to decide, given the present state of this section, of whose metalwork little is preserved (PLATE 3(e)). The lower two of these holes, it seems, were operated by the same band as the fifth hole from the top.

In FIG. 2 the pipes are also associated with their respective playing hands. These are obtained from the position of the knobs on the turning bands relative to their holes. The finger holes (apart from the thumb hole) are, of course, located on the upper side of the instruments. The knobs must be accessible to the fingers - especially to the index, according to my experiences on experimental instruments - both when the holes are open and when they are closed; this entails a position at about a right angle outwards from the hole in the turning band, i.e. clockwise for the right, counterclockwise for the left hand. One observes that in the case of the Pompeii instruments the longer pipes were played by the left hand, the shorter by the right. Accordingly, there are four possible configurations, all of which consist of a longer and a shorter pipe: $1+2 ; 1+4 ; 3+2 ; 3+4$.

The finger holes vary in diameter, ranging from about 5 to $9 \mathrm{~mm} .{ }^{22}$ A certain amount of doubt arises where the outer, turning metal bands are missing, because their opening could have been somewhat smaller than the hole in the core they covered (in the graphics, such cases are indicated

\footnotetext{
${ }^{18}$ Gevaert (1881) 647 n. 2: 'L'instrument C a onze trous; quatre sont fermés $(1,4,5 \text { et } 6)^{\prime}$. In Howard's count the closed holes are 3,4 and 5, his first two being open: thus Gevaert's closed hole 1 is doubtless situated next to the end.

${ }^{19}$ The section containing the topmost two holes is now separate. May it have been turned around the axis of the instrument by $180^{\circ}$ even before Howard's photograph? This assumption would restore the usual configuration.
} 
by blurred hole rims). ${ }^{23}$ Other important values are the diameter of the cylindrical main bore $(9.5 \mathrm{~mm})$ and the thickness of the tube walls, to which the ivory core and the bronze layers of the mechanism contribute (about $2.35 \mathrm{~mm}$ in total). From these data, the theoretical pitches with mouthpieces of all possible lengths can be calculated with the help of dedicated software. ${ }^{24}$

Before doing so, however, it is worthwhile considering Howard's experimental results as well, since these and the computer-generated pitch estimates may serve to qualify each other. Howard's replicas must have been built on the basis of his published measurements (with possible exceptions due to misprints, miscopies or errors in manufacture); accordingly our first calculations must also start from Howard's figures. It is furthermore certain that Howard's experimental playing in order to establish the scale did not involve any sort of cross-fingering, nor 'covered' playing, but that the holes were opened and closed one after another, so that all holes below the one 'played' were left open as well. With these suppositions, we arrive at consistent scales with mouthpieces of the following effective lengths: Pipe 1:2.2cm; Pipe 2: $4.0 \mathrm{~cm}$; Pipe 3:2.4cm; Pipe 4: $2.9 \mathrm{~cm}$. These extensions may appear surprisingly small, and are in fact smaller than the figures given by Howard himself for the simple, bamboo clarinet-type reeds he used. But effective mouthpiece lengths can differ significantly from the physical lengths. Thus the differences need not translate into a comparable variation of actual extension.

Since the formulae yield not only scales, but absolute pitches, it is possible to compare our calculated scales directly with Howard's experimental results. Here it must be taken into account that his pitches are almost always rounded to the nearest modern semitone; only in special cases does he resort to quartertone notation. This borne in mind, our calculation for the most part accords well with his pitches, as FIG. 3 demonstrates. ${ }^{25}$

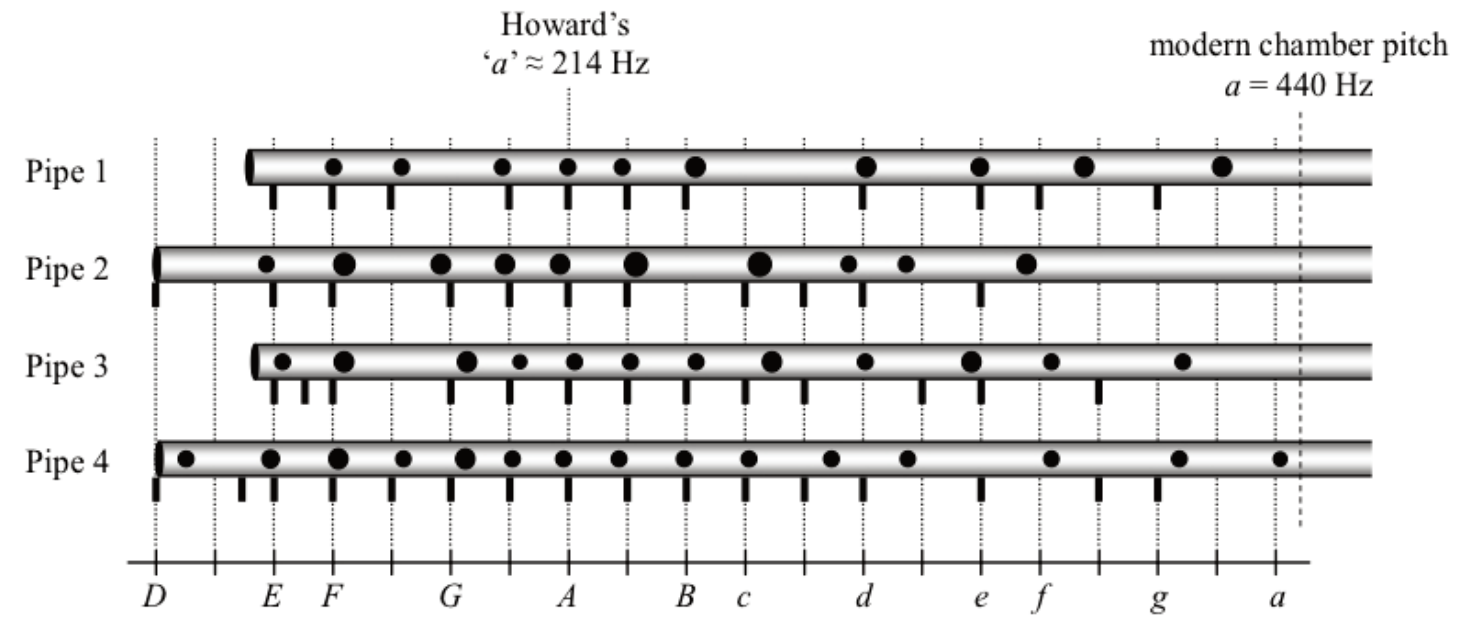

theoretical pitches, calculated from Howard's measurements

I notes obtained by Howard on replicas

FIG. 3. Pitches of Howard's replicas

${ }^{23}$ By such a technique, a consistent effective finger hole diameter could be ensured even if the operation of the band during playing was not exact; furthermore, the stepwise enlargement of the smaller hole might have formed part of a tuning procedure during manufacture.
${ }^{24}$ On the programme and the algorithms employed, $c f$. Hagel (2004) 380-1.

${ }^{25}$ In the subsequent charts the 'finger holes' indicate not their physical position on the instruments but their pitches, which are arranged logarithmically, equal distances indicating equal intervals. 
Most importantly, the relations between the individual pipes are identical in both approaches. Secondly, the present calculations agree with Howard's experiments that the heart of all four instrumental scales consists of a series of semitones - albeit ones whose size perhaps deviates significantly from the modern tempered semitone. Thirdly, what Howard quotes as an $a$, corresponds to a pitch of $214 \mathrm{~Hz}$ in our calculation. This implies a chamber pitch of about $430 \mathrm{~Hz}$, slightly below the present definition of $440 \mathrm{~Hz}$. It is close to the 'international standard' of Howard's time, ${ }^{26}$ and identi-

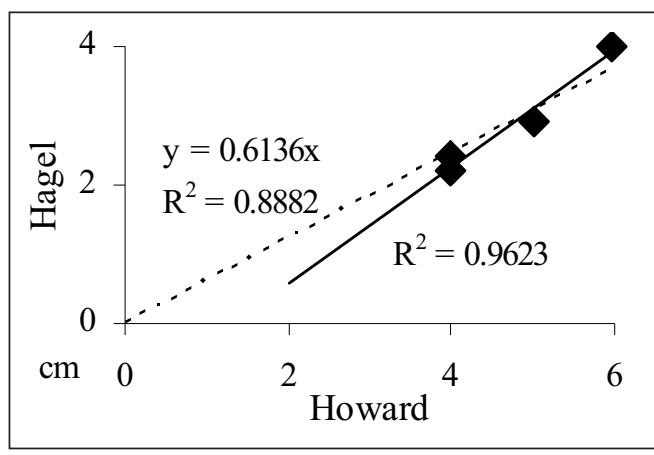

FIG. 4. Howard's physical reed lengths and the calculated effective values cal with the widely used 'Classical pitch'.

Furthermore, a comparison between Howard's reed extensions and our values reveals that they are analogous, and can be converted into each other by a linear transformation (FIG. 4). The data are compatible with the assumption that one unit of Howard's bamboo mouthpieces is equivalent to about 0.6 units of the calculated extensions ${ }^{27}$. In view of the cylindrical shape of the single beating reed, such equivalence supports the suspicion that the inner diameter of Howard's reeds was significantly smaller than the main bore. ${ }^{28}$

Nevertheless there are also substantial discrepancies between Howard's notes and the calculation. Two cases concern the lowest finger holes of Pipes 3 and 4. An explanation for Pipe 3 is easily found: both our calculated pitches for the finger hole and the pipe with all holes closed would have to be 'rounded' to $E$. If Howard obtained the same pitches and regarded the lower one as $E$ he naturally identified the higher one as something intermediate between $E$ and $F$, consequently notating it as the intervening quartertone. The case of Pipe 4 is more serious. Since all the other notes in this range of the pipe accord so well with our calculation, we must conclude that either Howard's hole position, or his identification of the note as ' $\times \mathrm{e}^{b}$ ' between ' $\mathrm{d}$ ' and ' $\mathrm{e}$ ', ${ }^{29}$ or both, are erroneous. As already stated, the crucial hole is now (almost) lost; yet enough of the next higher section survives to be sure that it cannot possibly have been placed so as to yield a pitch less than a semitone below that of the second hole. Thus it seems likely that the $E$ flat raised by a quartertone, ' $\times \mathrm{e}^{\mathrm{b}}$ ', is actually a misprint for a flattening by a quartertone.

The most alarming disagreements, however, appear in the highest parts of the scales, where Howard records much lower pitches than we would expect from our mathematical approach to the instruments' physics, up to more than a tone in the extreme cases. Actual flattening of high aulos notes in comparison to calculations is a phenomenon not unknown to the present author, but not to such a great extent. ${ }^{30}$ Perhaps the effect is mainly due to Howard's employment of a single reed with the relatively thick walls of a bamboo rod, ${ }^{31}$ which produces a step-like reduction of tube diameter, and consequently influences the oscillation regime of the higher finger holes most strongly, where the reed cavity constitutes a larger proportion of the vibrating air column. On the other hand, we must not expect that the respective calculated values are very exact either. Any reed's particularities exert stronger influences on a short tube; on top of this, the results of the calculations for very high holes are sometimes strongly affected by variations in other parameters which we cannot ascertain with sufficient accuracy. This is, however, true especially for the small top holes of Pipe 4, about which Howard did not know. For the larger ones currently under

${ }^{26}$ Howard (1893) 52, 'compared with the standard pitch'.

${ }^{27}$ In the chart the continuous line represents the linear regression $(y=k \cdot x+c)$; the dotted line the regression under the assumption of direct proportionality $(y=k \cdot x)$.
${ }^{28}$ A decrease of the cross-section to $61 \%$ of the main bore would imply a reduced internal diameter of $7.4 \mathrm{~mm}$.

${ }^{29}$ Howard (1893) 52.

${ }^{30} C f$. Hagel (2004) 382, with reference to Byrne (2000) 280 and 284 fig. 2.

${ }^{31} \mathrm{Cf}$. Howard (1893) 51. 
consideration, the calculated pitches are very likely much better than those obtained with Howard's reeds, although we must reckon with decreasing precision in the highest region.

From these preliminary considerations we can proceed to the evaluation of the instruments in the light of our newly obtained measurements. Here we face a problem unknown in calculations for simple auloi, or those carried out above for Howard's replicas. In largely chromatic instruments, it is utterly unlikely that for any finger hole played the entire row of semi-tone-spaced holes below was left uncovered by the turning bands. Rather, we must reckon with various configurations of open and closed holes for different pieces, and for different sections of modulating pieces, each configuration producing one specific scale. The effects of these configurations, which are equivalent to cross-fingering, are not very large, wherever the diameter of the highest open hole approaches that of the main bore; nevertheless we must pay attention to the effect if possible - especially to avoid accumulation of errors, since owing mainly to the state of the artefacts not all basic data could be established with sufficient precision. Presupposing particular scales would of course amount to begging the question. Instead, a mechanical rule must be adopted that at least roughly reflects musical practice. On entirely chromatic instruments, a good solution would be to open only every second hole, always closing that immediately below the played one. With the specific design of the Pompeii pipes, this approach needs some qualification wherever it would bring about intervals too large, i.e. significantly larger than a tone. Consequently I have decided to treat the lower neighbouring hole as shut whenever the interval in between was, roughly estimated, closer to a semitone than to a tone (i.e. smaller than three quarters of a tone), provided that the ensuing interval was closer to a tone than to a third (i.e. not larger than five quarters of a tone). The necessary implication of a diatonic standard, apart from the absence of a viable alternative, seems safe from a musical point of view: diatonic music was rightly considered as preceding the other ancient Greek genera ${ }^{32}$ and had virtually ousted these in Roman times. ${ }^{33}$ It is beyond reasonable doubt that the Pompeii instruments would have also played diatonic music, and highly likely that this was their main, if not exclusive, function.

Starting from the stated assumptions, to obtain a maximum number of calculated pure octaves, fifths and fourths within (and between) the instruments, the following effective reed extrusions are now required, which are slightly longer than those inferred above for Howard's replicas: Pipe 1: $3.0 \mathrm{~cm}$; Pipe 2: $4.5 \mathrm{~cm}$; Pipe 3: $3.1 \mathrm{~cm}$; Pipe $4: 3.5 \mathrm{~cm}$ (it must be kept in mind that the physical size of the reeds will have differed from the given values, owing, among other reasons, to the noncylindrical geometry of the double reed). ${ }^{34}$ The resulting usable consonances down to the fourth within and between the pipes are listed in the appendix. We know from Theophrastus that the reeds for the two pipes of an instrument were not interchangeable, ${ }^{35}$ and were therefore of dissimilar acoustic properties. Naturally the 'higher' reed goes into the higher pipe, and this seems in accord with the Pompeii instruments, of which the two longer ones require the greater effective lengths. ${ }^{36}$ Interestingly, while the bulb plus reed insert of Pipe 2 is shorter than it is in the other pipes, this difference must be counterbalanced by an (acoustically) longer reed.

${ }^{32}$ Aristox. Harm. 1.19, p.24.20-25.4 Da Rios; $c f$. the purely diatonic Near Eastern scales known from cuneiform sources (e.g. Kilmer (2001); West (1994); Franklin (2002); Hagel (2005b)).

${ }^{33}$ Cf. West (1992) 164-6. The proportion of extant melodies including a pyknon falls from about $75 \%$ in the time between 300 and $100 \mathrm{BC}$ to less than 5\% during the first centuries of the Christian era.

${ }^{34}$ For the Louvre aulos, calculated effective reed extrusions of $4.5 \mathrm{~cm}$ and $4.3 \mathrm{~cm}$ give the best results ( $c f$. Hagel (2004) 387 , diagram $2: 4.6 \mathrm{~cm}$ and $4.2 \mathrm{~cm}$ ). I can play the calculated pitches with cylinder-ended double reeds extruding $4.0 \mathrm{~cm}$ and $3.7 \mathrm{~cm}$; note that the position and pres- sure of the lips as well as the air pressure contribute also to the mouthpieces' effective lengths.

${ }^{35}$ Theophr. Hist. plant. 4.11.7.

${ }^{36}$ On the Louvre aulos, whose pipes are of equal length, the 'higher' reed is needed for the pipe with higher finger holes. The most unambiguous evidence for a definitely Greek instrument with pipes of unequal length is the Pydna aulos (Banou (1998)). Similarly, the pieces from which the Copenhagen 'aulos' is assembled (Olsen (1967)) cannot be made into two pipes of equal length. The Elgin pipes (Schlesinger (1939) 411-20; pl. 17) are also dissimilar, but it is not certain that they form a pair. 
As the next step, we must try to embed the instrumental scales into what we know about the system of ancient music. Here an obvious objection must be faced. The auloi were deposited in Roman Imperial Italy, while ancient music theory is entirely Greek. Although a native Italic music culture doubtless existed, no ancient author tries to analyse tonal structures other than those described by Greek theorists in the fourth century BC and earlier. Similarly all extant musical fragments are Greek. Is it then to be expected that Pompeian instruments fit in with our knowledge of ancient music at all? Quite probably it is, taking into account the nature of these particular instruments. Their expensive mechanism as well as their largely chromatic design - in the modern sense of the word - demonstrate that they belong to a high cultural level of musical life. Such instruments had originally been developed for the star performers of the late fifth and fourth century $\mathrm{BC}$, to meet the demands of increasingly modulating and chromaticized music. ${ }^{37}$ The festivals ensured that this 'New Music' became the recognized standard almost immediately; thus the modulating aulos was doubtless indispensable for the artists' guilds of the Hellenistic and Roman age. Festivals and guilds became the pillars of an internationalized musical culture, which comprised large parts of the Mediterranean. ${ }^{38}$ In origin and in nature, however, it remained predominantly Greek, barring the adoption of native musical styles as adequate expressions of civilized life. Consequently it seems worthwhile to search for 'Greek' scales in any instrument with possible affiliation to the higher strata of Hellenized culture, and therefore also in the Pompeii auloi.

Apart from the mere existence of a hole, one may take advantage of three additional clues to its function in a tonal system. First, its size: larger holes radiate sound waves more evenly, ${ }^{39}$ so it can be expected that holes of greater importance tend to be made larger than their neighbours. This criterion may however conflict with other considerations of design, for example, hole placement optimized for easy fingering, or regular spacing for maximal air tightness of the single bands. Secondly, whether a hole was open or closed when the instruments were deposited may shed light on its typical usage. Such evidence must, of course, be regarded with the utmost caution, and can at best serve as additional confirmation for conclusions reached otherwise. Much more promising is the third clue: the instances where two holes are operated by only one band, so that both cannot be open at the same time, have a considerable impact on the tonal capabilities of the pipes in question, and must have been related to the scales which they generally played.

The quest for a meaningful tonality is best started at Pipe 2, which is a long pipe (thus raising hopes for an important fundamental note), but equipped with relatively few finger holes in comparison with the other three items (so that we can expect a greater proportion of basic as opposed to accidental or modulating notes). We can express the scale of Pipe 2 roughly by means of tones and semitones. From the lower end of the pipe up to the highest finger hole it runs as follows: TSTSSSTSSST. Obviously the instances of three semitones in a row are points of possible modulation. The entire series, however, cannot be accommodated within a continuous diatonic scale, simply because it does not repeat at the octave. In modern terms it must therefore be described as a mixture of at least two scales. If for convenience scalar steps are expressed in relative pitch absolute pitch being indicated by a vertical dash at modern $A=220 \mathrm{~Hz}$ - the instrument can be analysed as shown in FIG. 5.

The series of notes below the pipe represents a possibility that is especially intriguing in view of ancient theory, where two model scales were used side by side. Firstly there was the 'Greater Perfect System', extending over two octaves, in its diatonic variant similar to a run from $A$ to $a$ ' on the white keys of the piano. In addition, and providing for the most common type of modulation, there was the 'Lesser Perfect System', which consisted of three 'conjunct tetrachords', thus

\footnotetext{
${ }^{37}$ For the musical (r)evolution in the late fifth century and its connections with the aulos, $c f$. e.g. Wilson (1999).

${ }^{38}$ Note that beautiful examples of mechanical auloi from the Hellenistic age have been found in such remote
}

places (from a Graeco-Roman viewpoint) as Meroë (Southgate (1915); Bodley (1946)) and Bactria (Litvinsky (1999)).

${ }^{39}$ Cf. Benade (1960) 1606. 


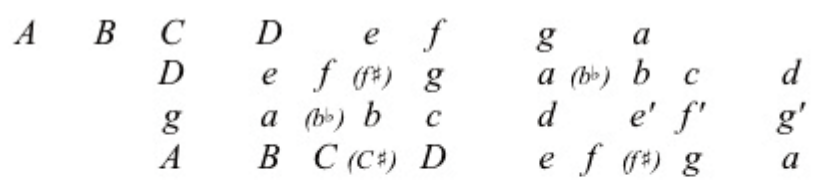

Pipe 2

$\vdots 220 \mathrm{~Hz}$

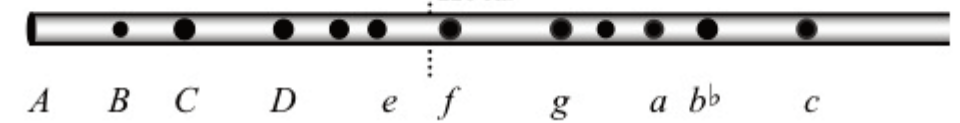

FIG. 5. Possible scales on Pipe 2

diverging from its greater brother in the upper part: once more in the diatonic form, $A-B-C-D-$ $e-f-g-a-b^{b}-c-d$. Pipe 2 can be understood as implementing such a scale without its highest note. But for the moment we must postpone any decision. This pipe does not only include modulating elements, but is, in some sense, a modulating pipe. It cannot be fully understood only by itself.

Pipe 3 complements it nicely. In combination the two pipes produce two continuous diatonic scales over their entire combined compass of an octave and a fourth. In addition, three further scales are available without the lowest minor third (which can be fingered only with great difficulty anyway, because of the large inter-hole distances). ${ }^{40}$ The five scales in question form a set of five continuous keys: each one a fifth higher or lower than the next. In Fig. 6 they are once more indicated by relative pitches.

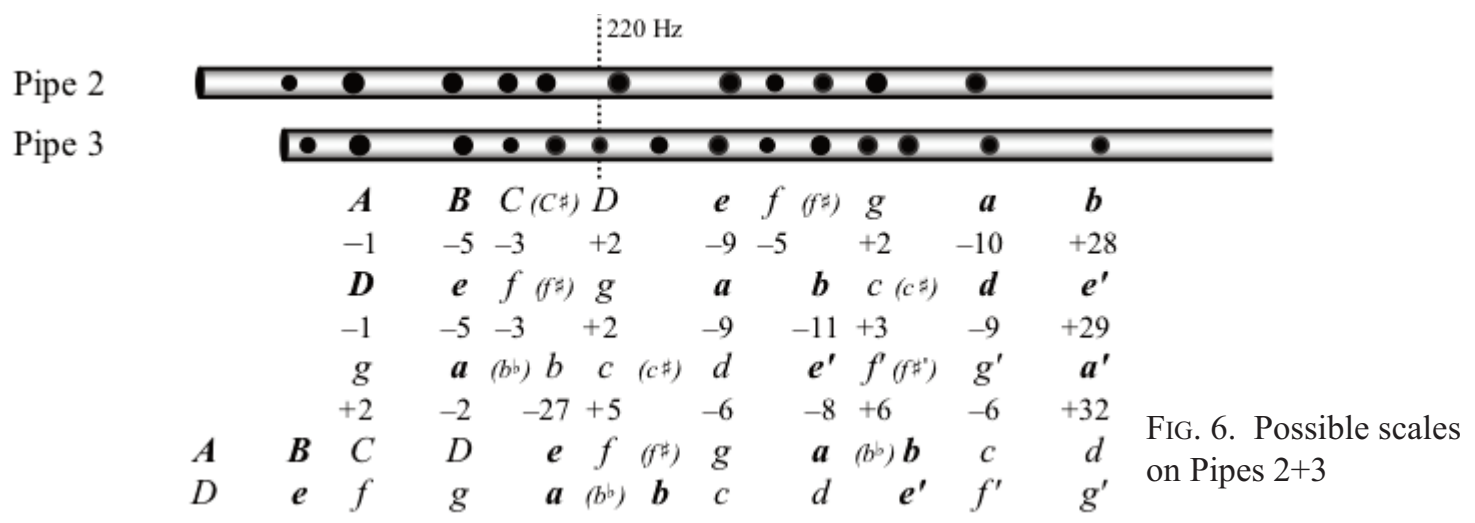

The notes are here accompanied by numbers indicating the divergences in cents of the calculated pitches from 'Pythagorean' scales, tuned in fifths and fourths throughout. ${ }^{41}$ This choice was made not out of some preconception about the 'ideal' aulos scale, but simply because modulation, proceeding in fifths and fourths as well, automatically gives rise to such a tuning. Above all, modulation governs the relation between the so-called 'fixed' notes, which are of structural primacy in ancient scalar theory, constituting the boundaries of the tetrachords into which scales were traditionally analysed. Thus they form the tonal framework; the intervening 'movable' notes define the 'genus' and could furthermore be tuned to a variety of 'shades'. Consequently the divergence from an ideal scale is of special interest for the 'fixed' notes, which are printed in bold in the diagram.

One common feature of the five possible scales is that their highest note is between a seventh and a quarter of a tone too high. The finger hole is, however, one of those where we do not know whether the actual diameter was smaller than it appears without the outer metal layer - which would have lowered the pitch. In addition, we should also reckon with a realistic amount of mouthpiece-induced flattening. ${ }^{42}$ More serious is the case of the third highest hole on Pipe 3. Although

${ }^{40}$ The distances between the four lowest holes of Pipes 2 and 3 are about: $3.0 \mathrm{~cm}-5.3 \mathrm{~cm}-2.4 \mathrm{~cm}$. In the lowest playing position this results in an extremely inconvenient span between middle and ring finger, which can be managed only by covering the holes not by the fingertips but by the fleshy parts between the joints of these fingers. Although this is a technique well known on single pipes in

many folk-cultures, it less practical on a pipe held in only one hand and makes it virtually impossible to operate the collars with the two fingers in question.

${ }^{41} \mathrm{~A}$ cent is defined as the hundredth part of a tempered semitone and thus the 1200th part of an octave.

${ }^{42}$ A similar discrepancy of about 30 cents occurs on the highest note of the Louvre aulos (Hagel (2004) 382-3). 
it is needed for 'fixed' notes in the two extended scales, its pitch appears a sixth of a tone too low. Fingering problems cannot have been the cause: as a simple experiment shows, the middle finger can comfortably cover a hole several millimetres higher up. Might the low position of the hole indicate that the extended scales are not those for which the instrument was primarily meant? In the other scales it produces 'chromatic likhanoi, which have no predefined pitch, as they belong to the 'moving' notes of ancient theory. Against this there is the apparently low importance of the chromatic genus in Roman Imperial times. We will come back to this problem.

The total compass of the two pipes spans an eleventh. On a cylindrical pipe this is a vital interval, because it enables a skilled player to continue the scale upwards by producing the first available harmonics, which lie a twelfth above the fundamental mode. The same extensible fundamental eleventh is found on the Louvre aulos. ${ }^{43}$ There its internal structure accords with the lower part of the 'Greater Perfect System' from $A$ to $d$ (i.e. without the highest tetrachord, called hyperbolaion, 'in excess'). It is hardly a coincidence that one of the possible diatonic scales for the Pompeii Pipes $2+3$ instantiates the same structure. This corroborates the impression that these two pipes were intended as a possible pair.

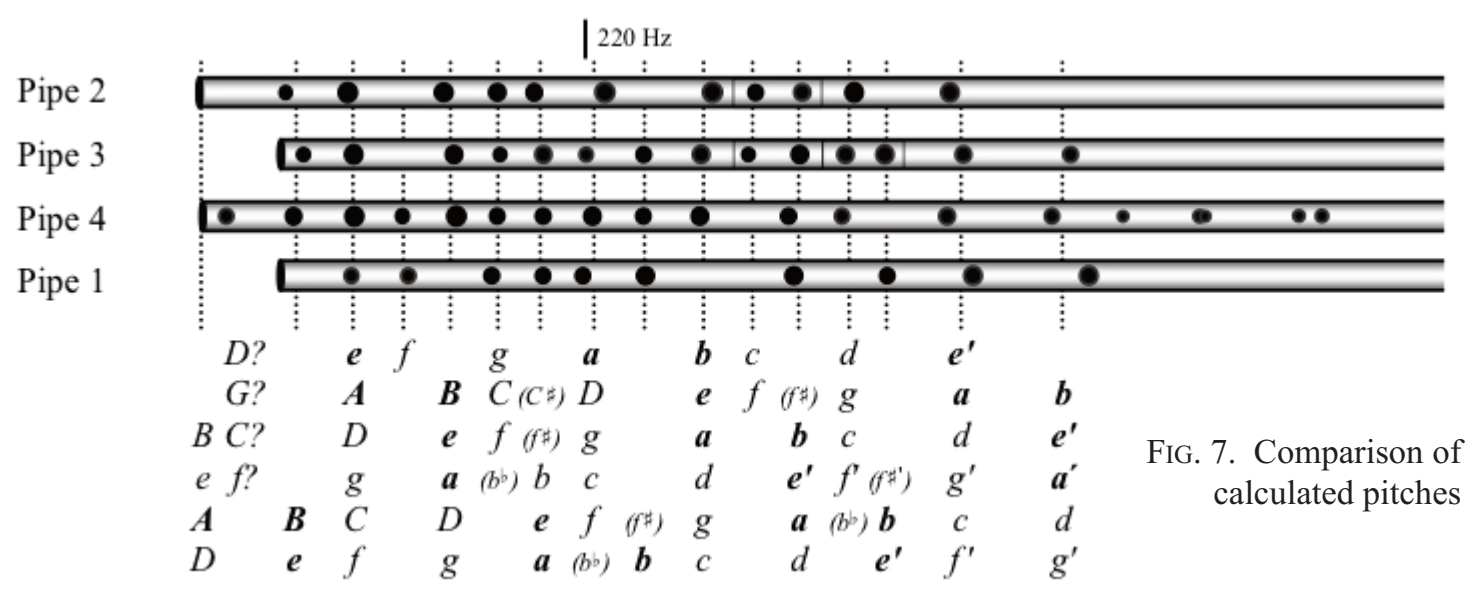

In FIG. 7, the two remaining pipes are related to the established structure. In spite of the numerous pitch coincidences, we do not know, of course, whether all four pipes form part of a uniform paradigm at all. ${ }^{44}$ If not, the extended chromaticism of Pipe 4 almost precludes the determination of a scale. But it seems a priori not unlikely that four instruments of such similar make that were found together adhere to the same pitch standards, even if they do not play exactly the same set of notes.

Within the double octave of the 'Perfect System', its central note, mesê, is also of central importance. In older times it seems to have functioned as the typical tonal centre; later it was still perceived as the pivotal point from which the function of notes in a scale and the scale's interrelation with other scales were understood. ${ }^{45}$ In the modern relative pitch notation adopted above, mesê corresponds to ' $a$ '. Out of the five 'keys' of Pipes $2+3$, it holds true for three that their mesai recur on all four instruments (namely for those ranging from $D$ to $g$, from $A$ to $d$, and from $A$ to $b$ ). In addition to these comes another scale that is realized only by the combination of Pipes 3 and $4\left(e\right.$ to $e^{\prime}$ ). Thus, out of the six notes shared by all four pipes, five are mesai (or possibly octave counterparts of mesai) of inferred scales; this adds some confidence to our preliminary analysis.

${ }^{43}$ Hagel (2004) 385; cf. Hagel (2005a) 84-6.

${ }^{44}$ Note that the mismatch of the lowest pitch of Pipe 1 is only apparent: the note in question was probably not sounded from the entire pipe, but from the lost hole discussed above ( $c f$. n.18), just as on Pipe 3.

\footnotetext{
${ }^{45}$ On the problem of 'thetic' versus 'dynamic' mesê, $c f$. Winnington-Ingram (1936), especially 6-9.
} 


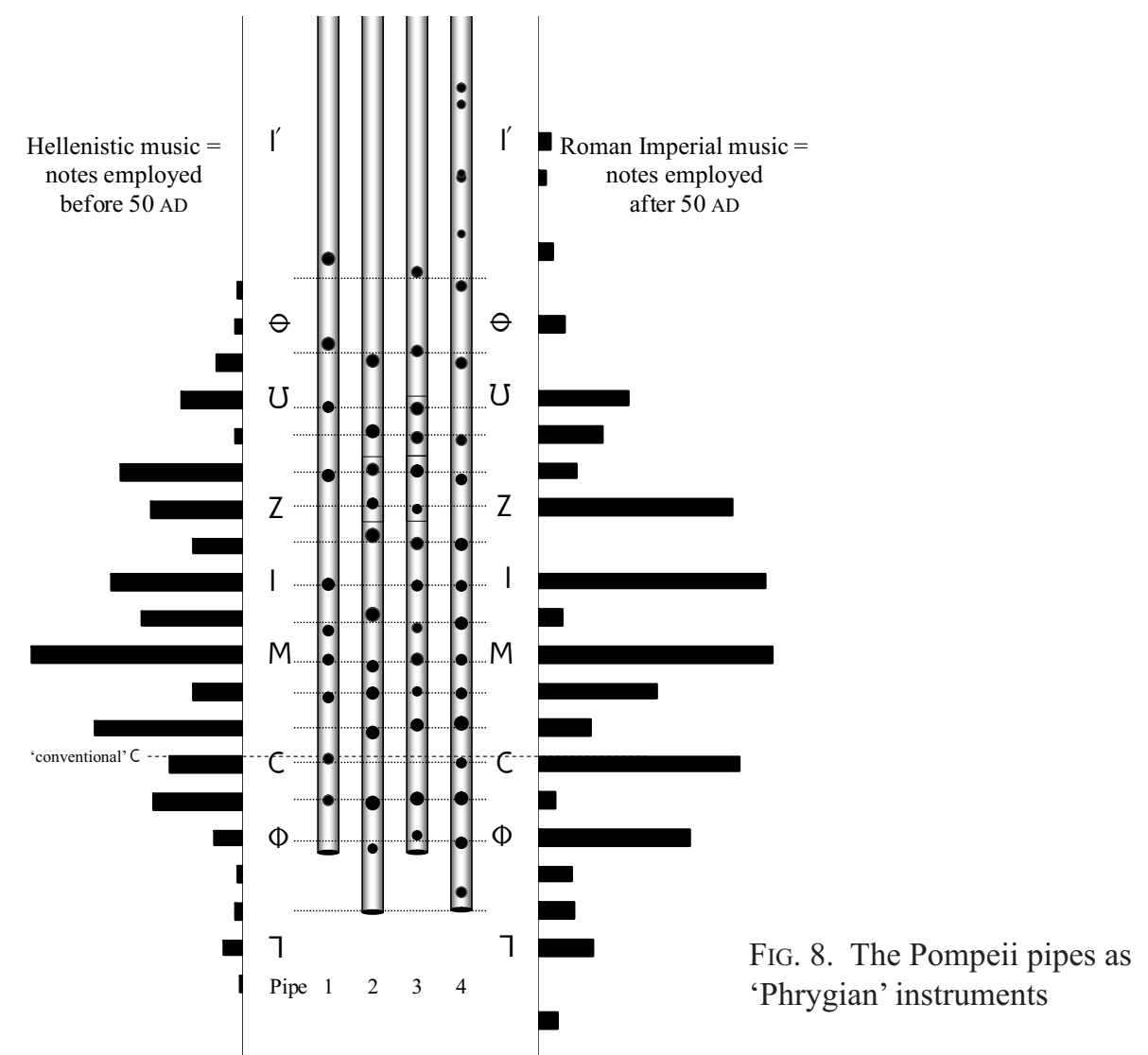

The question of correlating our 'keys' to those of the ancient system of tonoi brings us back to the topic of absolute pitch. Obviously the ancient notation implied a conception of roughly standardized pitch, much as modern staff notation does. ${ }^{46}$ Nonetheless one must bear in mind that modern chamber pitch varied over place and time by much more than a tone; so the idea of 'fixed' pitch must be treated with caution. In the canonical equation, based on the evidence of the extant vocal scores, the ancient note CC (Lydian hypatê mesôn) is set to about modern $f$ \# below middle $c$, or a bit lower. ${ }^{47}$ We will take this value as a starting point, ascribing it a frequency of $180 \mathrm{~Hz}$ (a quartertone below $\left.f^{\#}\right)$. From this rough identification, it becomes clear that the Pompeii instruments' compass is in very good agreement with the vocal range of the ancient musical fragments: ${ }^{48}$ compare FIG. 8, where the evidence is split into the time before and after the destruction of Pompeii. ${ }^{49}$ The distinction is more significant than one might think at first. Our data allow us some

${ }^{46}$ For an introduction to ancient notation, $c f$. West (1992) 254-63. The notes existed in two variants, the 'vocal' and the 'instrumental' notation, and are traditionally referred to by the two corresponding signs. The shapes are similar only in the case of CC.

${ }^{47}$ Cf. West (1992) 273-6.

${ }^{48}$ In interpreting the Louvre aulos, I have assumed that it played an octave above the male voice, and concluded that its key is Hypolydian (Hagel (2004) 384; with 388, diagram 4). The Pompeii pipes prove that professional instruments played in the 'correct' range, and the instrument lengths in the iconographic sources imply the same (I shall address the pictorial evidence in a future study). Still, there is no alternative key for the Louvre aulos (the highest ancient tonos, the Hyperlydian, is rather too low; furthermore, we never find the Hyperlydian treated as a scale in its own right). Thus it either has to remain an octave instrument, or it was not intended as participating in the tonos system at all.

${ }^{49}$ In the diagram similar pitches are combined, even if written with different notes (which regularly occurs in the musical documents, owing to the practice of 'functional' notation). The vocal signs of some important notes are printed just for orientation. The extant documents are edited in DAGM (add now Bélis (2004) and Yuan (2005)). Note that the difference between the assumed date of AD 50 (for technical reasons) and the destruction of Pompeii AD 79 has no effect, since no documents are dated to the intervening period. Within each column, bar lengths indicate raw frequency; in order to facilitate comparison, however, the bars for 'Hellenistic music' have been scaled to $133 \%$ of the 'Roman Imperial' unit. 


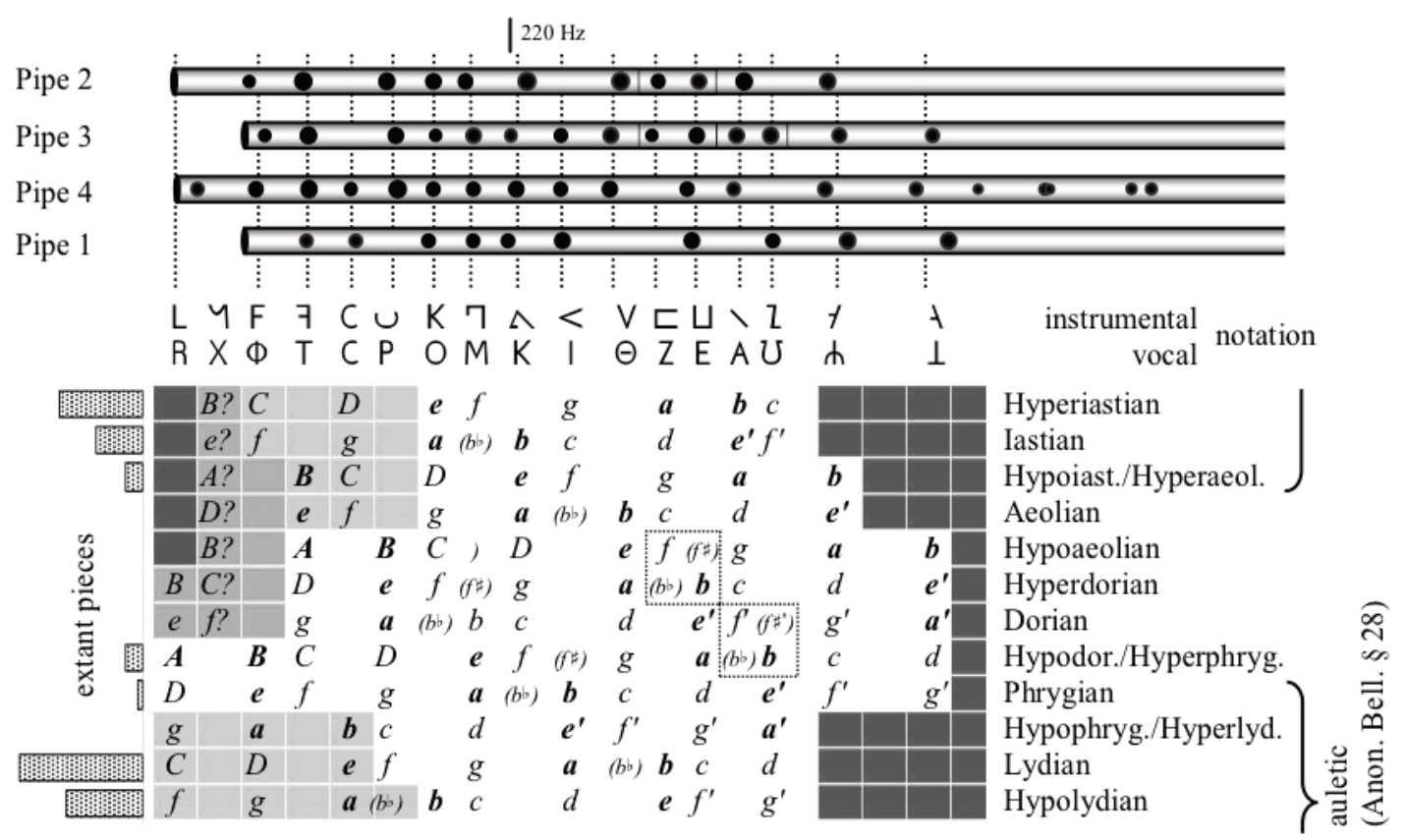

FIG. 9. Scalar implications of the 'Phrygian' hypothesis

insights into Hellenistic composition of the third and second centuries BC. Many more melodies are extant from the Roman era, but here the evidence starts in the second century AD. In the intervening two centuries profound changes took place: the old triad of Dorian, Phrygian and Lydian tonoi apparently fell out of use, hand in hand with the obsolescence of chromatic music. Only Lydian kept its place as the natural key. The others were replaced by newcomers, which related to the old tonoi much as our sharp keys relate to the flat keys. The eruption of Vesuvius fell right within the later part of this period of change. A priori one might therefore expect the Pompeii auloi to reflect the later type of music. On the other hand, it cannot be taken for granted that the picture derived from the extant fragments applies to all types of music, or particularly to aulos music. Nor do we know how old the instruments were when they were buried in the course of the catastrophe; in any case, as they had apparently not been abandoned, they were very probably compatible with the demands of first-century music.

The straightforward application of the 'conventional' pitch would assign the Lydian hypatê CC to the second hole from the end of Pipe 1, and to the fourth hole of Pipe 4 (see FIG. 8). Notably it would be missing from the other two. Consequently these would not be able to play in Lydian, the most prominent key in the extant ancient melodies. On this assumption the set of pipes modulates mainly between Phrygian and Dorian. The implications can be read from FIG. 9, where, for all twelve keys, the contiguous scales playable with the various possible combinations of the pipes are indicated by different shades of grey, the white part indicating the region common to all combinations. ${ }^{50}$ The pivotal note would be the Phrygian mesê, $\mathrm{M} 7$, which fits the traditional association of the aulos with Phrygian music. Thus the pipes would belong to the older, Hellenistic, paradigm. ${ }^{51}$

But this interpretation, enticing as it may be, cannot stand closer inspection. Firstly, it is disconcerting that the commonly playable section from the Dorian scale does not at all relate to the

${ }^{50}$ The twelve functional keys of the modern keyboard cover modulations at every semitone step within the octave. In antiquity just such a complete system was devised by Aristoxenus and incorporated into the notational system accordingly. The ancient numbers of keys, namely thirteen or fifteen, need not concern us in the present con-

text, since those in excess of twelve were created merely as octave doublets.

${ }^{51} C f$. the association of Pipe 3 with the First Delphic Paean (DAGM 20) by Curtis (1914) 102 (but $c f . \mathrm{n} .12$ above). 


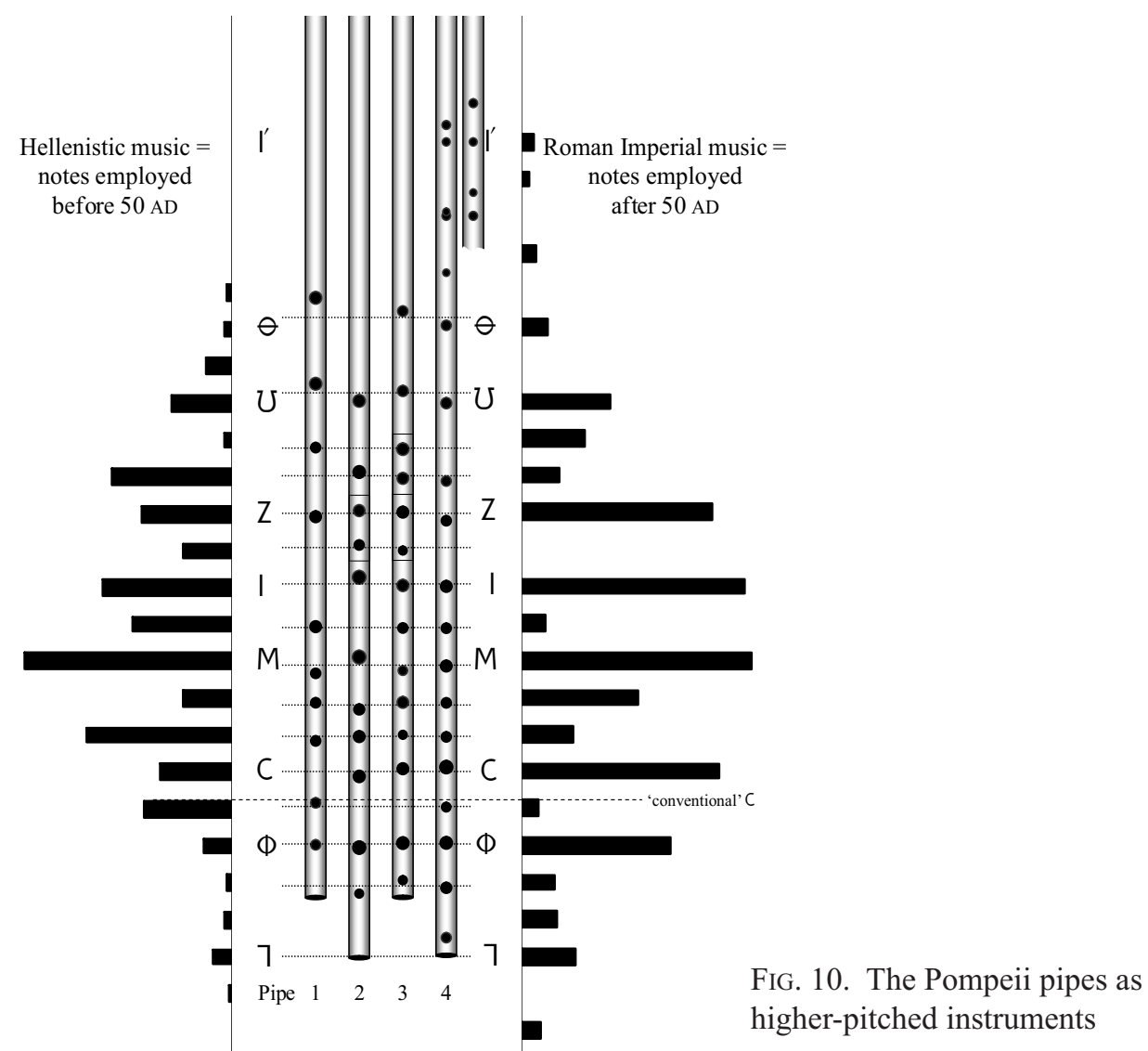

range from $e-e^{\prime}$, the famous Dorian 'central octave', which doubtless played an important role in earlier Greek music. Secondly, the Lydian, whose presence must be expected on a modulating Hellenistic pipe ${ }^{52}$ ranges among the keys for which the instruments would be least adapted. On top of this, the available holes do not even account well for the distribution of notes in earlier music: $U$, for instance, occurs about twice as often as the note a semitone above, but the latter would be present on all pipes, the former only on two. Similarly, the prominence of the two notes between $C$ and $M$ appears reversed. More important still, of the five keys that would appear most prominent, three are never attested in the extant musical fragments, and the remaining two are also extremely rare. From the chart printed leftmost in FIG. 9, which gives the distribution of keys in the surviving musical documents, it transpires that the 'Phrygian hypothesis' is in polar opposition to this important aspect of musical evidence. Finally, it is contradicted by literary evidence. Of the anonymous treatises originally published by F. Bellermann, which deal with various, mostly practical, aspects of music, one provides a list of keys for different types of music. For the aulos, it indicates a contiguous range of seven keys, from Hyperaeolian to Phrygian ( $c f$. the bracket in FIG. 9 , to the right). Of these, the hypothesis under investigation accounts for not more than one. It follows that in order to uphold this specific pitches-to-notes equation, one would be bound to posit a musical style unknown to all other available sources.

A different interpretation is therefore preferable. In FIG. 10, the ancient notes are shifted one semitone higher, so that their pitch falls almost a quartertone above the upper limit conventionally assumed. Now all notes of importance are well represented on the pipes - and this is true for both

\footnotetext{
52 The invention of the modulating aulos - about half a millennium before Pompeii was destroyed - is reported to have enabled the playing of Dorian, Phrygian and Lydian on one instrument (Paus. 9.12.5; $c f$. Ath. 631e, p.394.3-7 Kaibel).
} 


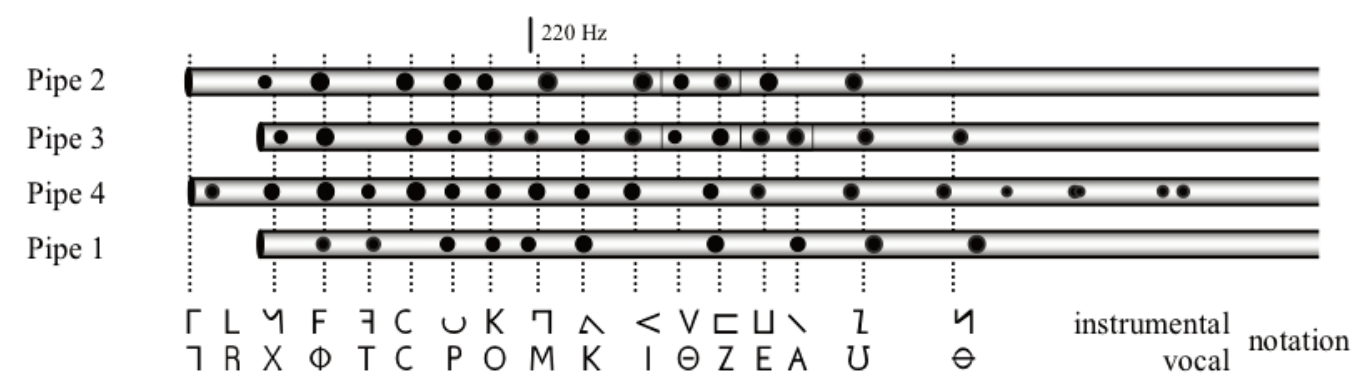

\begin{tabular}{|c|c|c|c|c|c|c|c|c|c|c|c|c|c|c|}
\hline \& & & $B ?$ & C & & $D$ & & $e f$ & & $g$ & $a$ & $b \quad c$ & & & Hyperdorian \\
\hline .ֶ. & & $e ?$ & $f$ & & $g$ & & $a$ & $b$ & $c$ & $d$ & $e^{\prime} f^{\prime}$ & & & Dorian \\
\hline \pm & & $A ?$ & & $\boldsymbol{B}$ & $C$ & & $D$ & $e$ & $f$ & $g$ & $a$ & $b$ & & Hypodor./Hyperphryg. \\
\hline Еี & & $D ?$ & & $e$ & $f$ & & $g$ & $a$ & $\left(b^{b}\right)$ & b $c$ & $d$ & $e^{\prime}$ & & Phrygian \\
\hline $\bar{x}$ & & $B ?$ & & $A$ & & $\boldsymbol{B}$ & $C$ & $D$ & & $\boldsymbol{e} \quad f(f \sharp)$ & $g$ & $a$ & $b$ & Hypophryg./Hyperlyd. \\
\hline & $B$ & $C ?$ & & $D$ & & $e$ & $f(f *)$ & $g$ & & $\boldsymbol{a}\left(b^{\circ}\right) \boldsymbol{b}$ & $c$ & $d$ & $e^{\prime}$ & Lydian \\
\hline & $e$ & $f ?$ & & $g$ & & $a$ & (b) $b$ & $c$ & & $d \quad e^{\prime}$ & $f^{\prime}\left(f^{\prime}\right)$ & $g^{\prime}$ & $a^{\prime}$ & Hypolydian \\
\hline 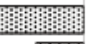 & $A$ & & $\boldsymbol{B}$ & $C$ & & $D$ & $\boldsymbol{e}$ & $f$ & $\left(f^{\sharp}\right)$ & $g$ & (bb) $\boldsymbol{b}$ & $c$ & $d$ & Hyperiastian \\
\hline 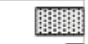 & $D$ & & $e$ & $f$ & & $g$ & $a$ & $\left(b^{b}\right)$ & $b$ & $c$ & $e^{\prime}$ & $f^{\prime}$ & $g^{\prime}$ & Iastian \\
\hline & $g$ & & $a$ & $\left(b^{b}\right)$ & $b$ & $c$ & $d$ & & $e^{\prime}$ & $f^{\prime} \quad g^{\prime}$ & $a^{\prime}$ & & & Hypoiast./Hyperaeol. \\
\hline & $C$ & & $D$ & & $e$ & $f$ & $g$ & & $a$ & b $c$ & $d$ & & & Aeolian \\
\hline & $f$ & & $g$ & & $a$ & & b $\quad c$ & & $d$ & e $f^{\prime}$ & & & & Hypoaeolian \\
\hline
\end{tabular}

FIG. 11. Notes and keys of the Pompeii instruments

the earlier and the later fragments. All the pitches that we find ubiquitously on every pipe are frequently encountered in one or the other of the two distinctive periods. Significantly, the lower limit now coincides with $\rceil$, which is the lowest note of many melodies. ${ }^{53}$ The highest finger holes seem also to make some sense, even if they lie above the normal vocal range (for Pipe 4, a second set of pitches is given for the top holes, calculated on the assumption that they are played with their lower neighbours left open; only thus is reasonable pitch difference achieved between the second pair from the top). The undivided tone between $U$ and $\theta$ corresponds to a lack of intervening notes in Roman Imperial music. The criterion of hole size confirms the present identification: large holes are now associated especially with the notes $\Phi \subset M I U$, all of which are of significant frequency. ${ }^{54}$

FIG. 11 once more correlates the resulting scales to the evidence from extant compositions and the Bellermann treatise. Now the instrumental scales best provided for are associated with the four most used keys, Lydian, Hypolydian, Hyperiastian and Iastian. In fact, these account for almost all music extant from the Roman era. ${ }^{55}$ Lydian and Hypolydian are available (at least) down to $\Phi F,{ }^{56}$ while the two Iastian scales take advantage of the entire instruments. Similarly, the five optimal scales occupy the centre of the seven auletic keys according to Bellermann's Anonymus.

The present interpretation also provides the key to understanding the three bands that operated two finger holes, so that only one could be open at a time. For the greatest part of the instruments' range such an arrangement would be impractical, since most adjacent holes are required at the

${ }^{53}$ DAGM 11, 12, 21, 23, 25 (citharodic, though), 39, 40, 41.2, 45.2.4-8, 47, 51, 53 fr. 1, 54 fr. 1, 58.

${ }^{54}$ The application of the criterion of open vs closed holes is complicated not only by the number of metal bands missing, but also by the fact that nicely alternating patterns are found only on Pipe 3 and the lower part of Pipe 4. These, at least, substantiate the proposed interpretation: on Pipe 4 the important notes $\Phi, C$ and $M$ stand out as open (together with the infrequent note below $\Phi$ ), while on Pipe 3 the rare semitones above C, M, I and Z stand out as closed. On Pipe 2 only the semitone above $I$ is shut - necessarily, since frequent $\mathrm{Z}$ is open with the rest.

${ }^{55}$ The only exception is DAGM 58 (Hypoiastian).

${ }^{56}$ This limitation depends on the exact position and size of the lowest hole on Pipe 4, and the question of a corresponding hole on Pipe 2 (both discussed above). Of the documents listed in n.53 above, four employ the note in question, RL, a semitone above $7 \Gamma$ : nos $12,21,25,45.2 .4-8$. 
same time within some scale or other. But not so the two pairs of notes which are actually joined by the aforementioned mechanism (in the figures indicated by separating lines on the pipes, and by squares in the tables of scales). Twice $Z \sqsubset$ is thus united with the note a semitone below. Within a continuous diatonic scale this pair appears only in Aeolian and Hypoaeolian. If our pipes reflect here a regular feature of aulos manufacture, this would explain why the range of auletic keys stopped at Hyperaeolian, as maintained by the anonymous treatise. Actually the lower of the two notes is almost never used at all in the extant fragments from the later period - with one notable exception in one of the few surviving instrumental scores. ${ }^{57}$ On the other hand, such a pipe design obviously precludes a chromatic tetrachord at this point (i.e. one like $a-b^{b}-b-d$ in the Lydian of FIG. 11), or at least would make its performance extremely clumsy. It must be significant in this context that such a tetrachord indeed does not appear in the musical documents, not even in compositions that are otherwise freighted with chromaticism. Where the two notes exist side by side within the same piece, they are separated by modulation, which physically corresponds to the turning of the band. ${ }^{58}$

The higher two-hole band on Pipe 3 switches between the notes Eป and $A \backslash$ (or whatever their pitch equivalences are in other keys), thus modulating mainly between the Lydian and the Iastian scales. Again the two pitches occur in a continuous diatonic scale only in keys that are never attested as such, namely in Dorian and Hyperdorian. Attestation within one and the same composition is scarce and mostly uncertain. ${ }^{59}$ At least in Roman Imperial diatonic music, an instrument design that rendered them mutually exclusive makes good sense.

With the connection to the ancient system of keys established we can now return to the problematic pitch that we obtained for the third highest hole on Pipe 3. A corresponding hole exists on Pipe 1, the size of whose effective aperture is certain enough. The fact that the respective calculated pitches are practically identical on both pipes would seem to exclude an error: in all probability the pitch of $A \backslash$ is lower on the Pompeii instruments than we would have expected on the grounds of ancient music theory. In searching for an explanation of such a divergence we must therefore resort to evidence from ancient musical practice. Proper intervallic relations were doubtless most important in the simultaneous sounds of the double pipes; unfortunately, however, the heterophonic accompaniment was apparently never notated. But there is a good chance that within a given composition the same intervals were, on the whole, prominent in the melody and in the accompaniment, thus unambiguously contributing the specific flavour of a 'mode'. Consequently, we should be able to infer a kind of intervallic hierarchy from the investigation of the melodies. In the case of our $A \backslash$, it suffices to examine the Hyperiastian and Iastian compositions: only there is the pitch in question regularly employed. Furthermore, we can content ourselves with those intervals that are both reasonably frequent and potentially resonant (if adequately tuned); these are

\footnotetext{
${ }^{57}$ The virtual absence of this note is all the more surprising as the pitch in question is the Lydian tritê synêmmenôn $(\Theta \mathrm{V})$, from the evidence of the ancient musical handbooks to be expected as the most typical modulating note in Lydian music. It appears once in DAGM 61 (P.Mich. inv. 1205).

${ }^{58}$ The two cases are clearly distinguished in the ancient notation: modulation demands the sign Z $\sqsubset$ for the higher note, while the identical pitch is notated as $\mathrm{H}>$ where it is part of a chromatic tetrachord. Modulation is found in DAGM 10 (P.Vindob. G 29825 a/b verso) and $D A G M 21$ (the second Delphic Paean). The lower note alone appears in DAGM 6 (P.Ashm. inv. 89/B 29-32); DAGM 8 (P.Zenon 59533); DAGM 20 (the First Delphic Paean, where the Phrygian significantly abstains from chromaticism, except in the synêmmenon tetrachord).
}

\footnotetext{
${ }^{59}$ In $D A G M 3$ (the Orestes papyrus), ZE $\triangle$ should probably be interpreted enharmonically; $D A G M 6$ has $\Gamma$ and $\Delta$, probably denoting the pitches in question, once in immediate succession; $D A G M 19$, if containing notation at all, has ZE $\triangle$, but is almost certainly not auletic; $D A G M 20$ once introduces $\mathrm{B}$, a pitch elsewhere avoided, for a special reason besides regular $\Gamma$ ( $c f$. Hagel (2000) 48-50); DAGM 22 (Mylasa) seems to contain both $\mathrm{A}$ and $\mathrm{E}$, but the tonality of the fragmentary, only provisionally published, inscription is not established; in DAGM 48b (P.Oxy. 4464, 3-8), a $\triangle$ besides ZE is doubtful. I shall argue on another occasion that the chromatic succession ZE $\triangle$ belonged to cithara music.
} 


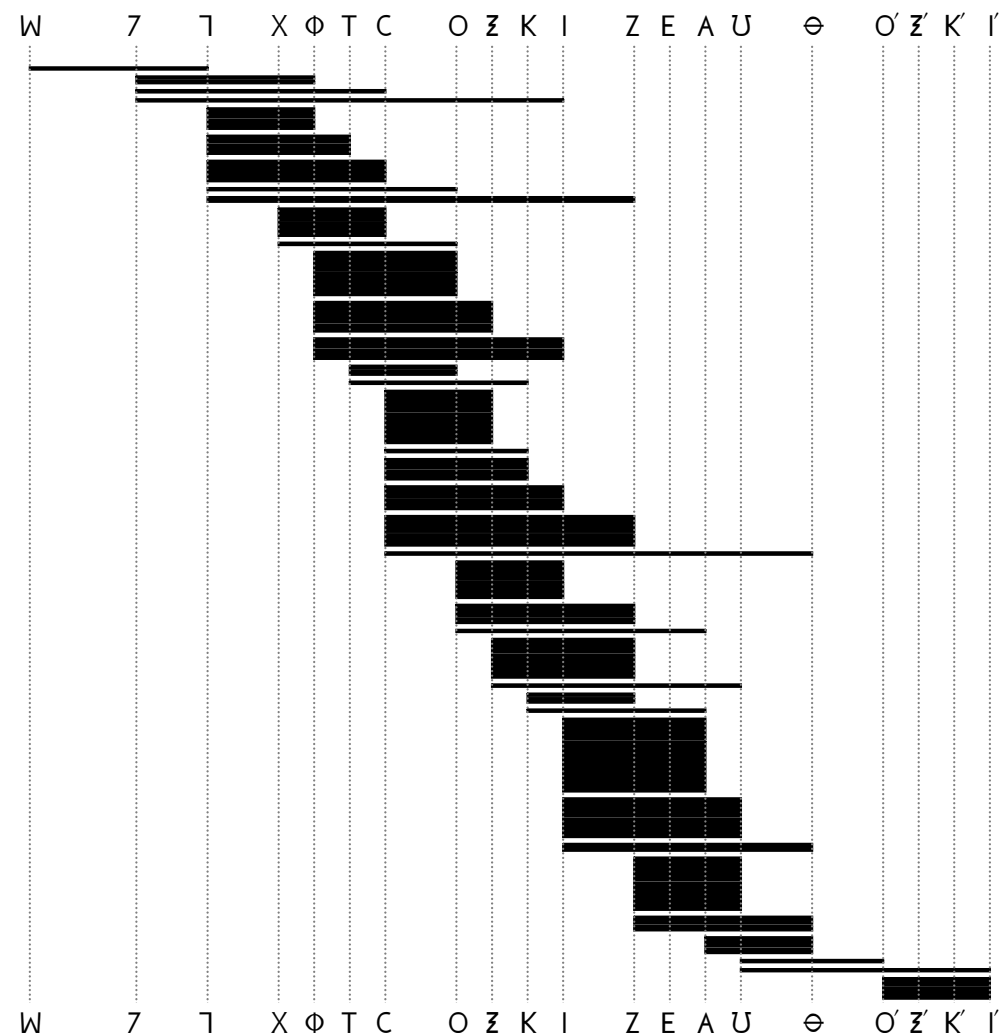

FIG. 12. Octaves, fifths, fourths and thirds in extant Hyperiastian and Iastian melodies

octaves, fifths, fourths and thirds. The evidence is presented in FIG. 12, where the thinnest lines stand for single instances of intervals, combining to thicker squares where the respective two notes are more frequently found in melodic succession. It will be observed that melodic fourths and fifths, although - quite naturally - less common than thirds, are not generally rare. The note $A \backslash$, however, almost never takes part in such an interval. ${ }^{60}$ Apparently, it was structurally connected to the rest not by fifths and fourths, but by the thirds it forms with $K<$ and $\ominus$ \. From the viewpoint of musical practice, one would consequently expect that these thirds were played as resonant intervals, rather than the fifth and fourth which ancient tetrachordal theory demands as pure. In fact this should hardly surprise us, since the existence of practical scales that violated the tetrachordal grid is attested as early as about $300 \mathrm{BC} .{ }^{61}$ Pure thirds at this point demand a note $A \backslash$ that is tuned about the ninth part of a tone lower than it would be in a 'Pythagorean' scale. Thus the divergence of calculated 32 cents, stated in FIG. 6, drops to an insignificant 10 cents. It emerges that the point where the instruments most obviously diverge from a uniform row of semitones (whether equally tempered or forming contiguous 'Pythagorean' scales) also confirms the proposed interpretation. ${ }^{62}$

${ }^{60}$ The two actual instances are found in the single melodic movement IKAO in DAGM 48.1-2 (P.Oxy. 4464.1-2), a composition from which we have no more than these four notes.

${ }^{61}$ Aristox. ap. ps.-Plut. Mus. $1145 \mathrm{~d}$.

${ }^{62}$ Another interesting case is the fifth hole from the lower end of Pipe 1, which also appears very low. If this pipe is rightly interpreted, the absence of $C C$ and $\mathrm{I}<$, both important in Lydian and Hypolydian, makes it an Iastian instrument, probably modulating in the direction of the Aeolian keys. In this context, the pitch in question (labelled $M 7$ in the figures) must be written as $Z \searrow$. It appears only in combination with $\mathrm{OK}$ a semitone below. Consequently, the lower neighbouring hole would generally be open, too, which slightly raises the pitch of $\bar{Z}$ in comparison with our initial calculation (namely by a calculated 11 cents). On the other hand, the note in question is here not part of the tetrachordal framework but defines the two lower intervals of the diatonic tetrachord; we know from Ptolemy that in second-century cithara music, at least, there existed a strong predilection for a low tuning of this note, resulting in a small semitone (i.e. by 27 cents smaller than the 'Pythagorean' semitone; $c f$. Hagel (2006)). Noticeably, only on Pipe 1 is the finger hole in question actually closed, which might also be due to its secondary status on an Iastian instrument. 


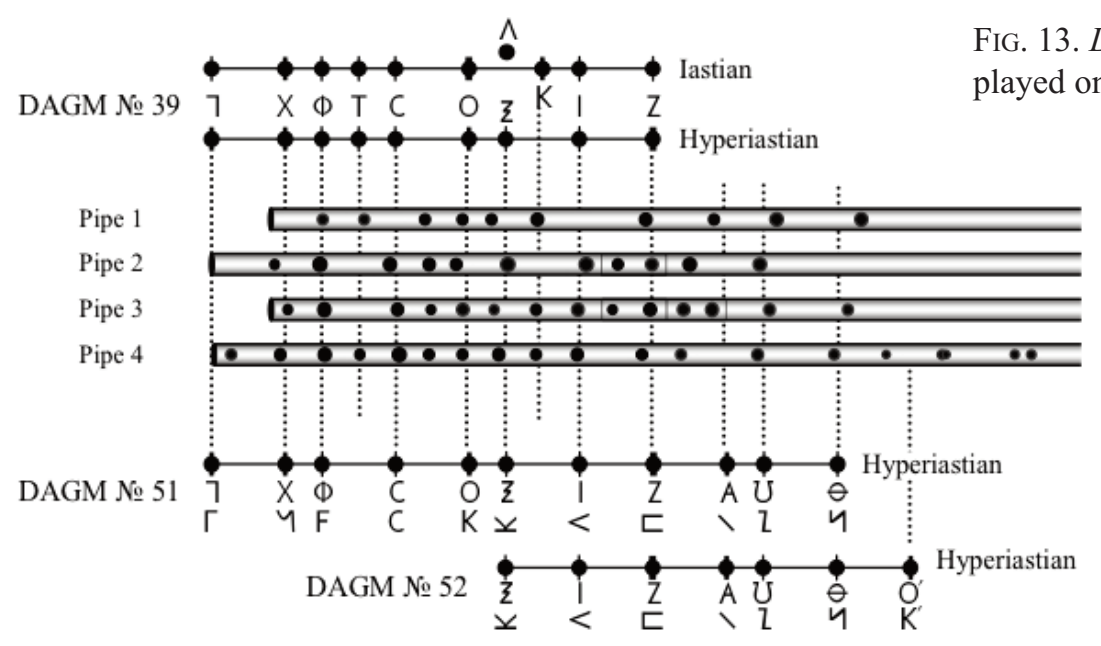

All in all, it seems a reasonably firm conclusion that the Pompeii instruments implement the typical tonality of their time. Their pitch is rather high, almost a semitone above what we have termed the 'conventional' assumption. Still, the correspondence of the two pitch values gained in entirely different ways is satisfactory enough in the reconstruction of a historical musical system that extends over a thousand years.

Two selected documents will serve to demonstrate the close affinity between Roman-era tonality and the Pompeii pipes. The first is a tragic composition from Oslo Papyrus 1413 (DAGM 39), musically the most complex piece surviving from the Roman Imperial period. It modulates between Hyperiastian and Hypoiastian, mediated via Iastian proper. FIG. 13 illustrates how the Pompeii pipes provide all necessary notes. Of the four possible combinations of pipes three will work; only that of Pipe 3 and 2 must be excluded. The Oslo Papyrus is of special interest also because it exemplifies the employment of the note $T$, which is not part of the four keys in their diatonic form. ${ }^{63}$

At the bottom Fig. 13 displays the notes of two instrumental pieces contained in Berlin Papyrus 6870 (DAGM 51f). Both are Hyperiastian, but of very different compass, and have been argued as representing aulos rather than lyre music. ${ }^{64}$ Once more the Pompeii instruments are equipped with all necessary finger holes. Those of Pipes 3 and 1 are confined to the range of no. 51, as they do not go beyond the Lydian nêtê diezeugmenôn. Even so, the highest note of no. 52 $\left(K^{\prime}\right)$ was probably available on Pipe 2 also, namely by overblowing the entire tube. ${ }^{65}$ The finger holes of the most elaborate pipe, Pipe 4, ascend even higher. Owing to their extreme position and unclear metalwork, as well as the increasing influence of the mouthpiece, their true pitches and functions are not easily determined; most likely they played $\mathrm{O}^{\prime} \mathrm{K}^{\prime}$ and the semitone below, perhaps $I^{\prime}<'$ and some note in its vicinity.

The coincidences with the papyri discussed confirm that the structure of the Pompeii auloi fits in with typical tonal structures of the Roman Imperial period. The question whether the exact melodies, which were found in Egypt, could be played on these instruments is another matter. If so, one can only speculate how this was done. As regards the vocal scores, we cannot simply assume that every sung note was redoubled by the accompanying instrument. Naturally the instrumental pieces are a more reliable guide to instrumental capabilities. Unfortunately, though, there is still no consensus about the possible relations of the two pipes of one aulos, but they were most

${ }^{63}$ Similarly, the Pompeii pipes hold all notes for the Hypoiastian DAGM 58 (P.Oxy. 4467).

${ }^{64}$ West (1992) 321.
${ }^{65}$ Note that this is possible when playing in the high range by closing all finger holes below the highest six by means of the metal collars. Is it mere coincidence that no. 52 does not go lower than these six holes of Pipe 2? 


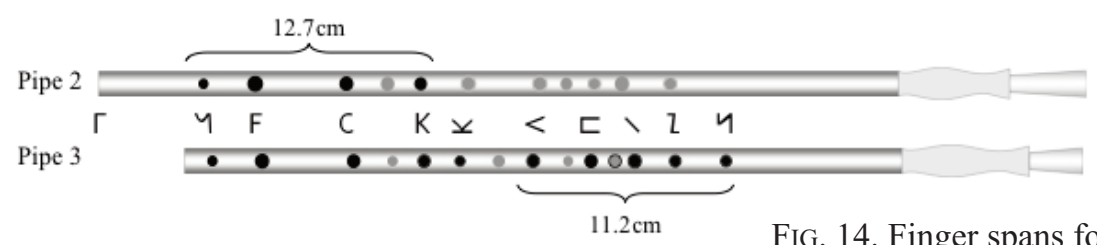

FIG. 14. Finger spans for $D A G M 51$ on Pipes $2+3$

likely not the same on all types. Continuous unison, at least, can be ruled out. ${ }^{66}$ Generally there are two options. One pipe, naturally the louder one, may have played the melody, while the other provided some kind of accompaniment, which might have been anything from a varying drone to a sophisticated intervallic technique. Alternatively, the melody would be distributed between the pipes; this makes a larger pitch range more easily available, but it is difficult to see how melody and accompaniment would have been distinguished (a 'primitive' solution is a common drone note, always supplied by the pipe not busy in melodic play).

The way the Pompeii pipes at some points complement each other might suggest rather the latter option: neither of the two Berlin instrumental pieces could be played on just one of them. The diatonic Hyperiastian eleventh of no. 51 is available only on a combination, and even for the restricted ambitus of no. 52 at least one note appears to be always missing. On a combination of Pipes 2 and 3, however, all the notes of no. 51 can be accessed even without operating the mechanism during performance. ${ }^{67}$ FIG. 14 indicates closed holes and fingering positions; the spans are manageable, although the lowest note on Pipe 2 requires some skill. ${ }^{68}$

All this, it must be remembered, is speculation. The musical papyri and the Pompeii instruments illuminate small aspects of a complex musical culture ranging over centuries and a vast geographical area. By accident they provide our primary evidence for some questions. We cannot choose, but we must not expect them to elucidate each other in a simple way. If it is plausible that they belong to a common tonal paradigm that permeates the first centuries of our era, this is almost as much as we could hope.

STEFAN HAGEL Austrian Academy of Sciences, Vienna

\footnotetext{
${ }^{66}$ Apart from the archaeological evidence that all pipes forming certain or possible pairs are dissimilar, and a number of ancient texts that speak of intervallic play ( $c f$. e.g. Barker (1995)), it makes no sense to use two pipes that are not fixed together for unison music. Where only the exciting effect of blending two almost identical pitches is sought, as in the Egyptian midjweh, the two pipes are aligned so that each finger stops two corresponding holes; thus up to eight holes can be fingered instead of only five.
}

\footnotetext{
${ }^{67}$ On the other hand, the melody of no. 51 contains no movement that one hand could not execute. On a longer variant of Pipe 3, on which the low $\urcorner$ were also available, the entire melody could apparently be confined to one pipe.

${ }^{68}$ In the extant part of the score there are two instances of this lowest note $(\Gamma)$ in immediate succession. In that context, however, the second lowest note ( 4 ) is missing; having its hole closed by the collar in advance would eliminate any difficulty.
} 


\section{APPENDIX. CALCULATED UNISONS, OCTAVES, PURE FIFTHS AND FOURTHS WITHIN AND BETWEEN THE POMPEII PIPES}

Intervals are listed up to an error of 20 cents.

Each line in the tables gives from left to right: the interval (1/1: unison; 2/1: octave; 3/2: fifth; 4/3: fourth); the open finger holes counted in ascending order from the lower end, with 0 for the note produced from the entire tube with all holes closed; the calculated divergence from the pure interval in cents.

\begin{tabular}{|c|c|c|c|c|c|}
\hline Pipe 1 & & & $4 / 3: \quad 2$ & 7: & +0 \\
\hline $2 / 1: \quad 0$ & 8: & +13 & $4 / 3: \quad 4$ & 9: & -16 \\
\hline $2 / 1: \quad 3$ & 10: & -5 & $4 / 3: \quad 5$ & 10: & -11 \\
\hline $3 / 2: 4$ & 8: & -14 & 4/3: 7 & 11: & -7 \\
\hline $4 / 3: \quad 4$ & 7: & +3 & $4 / 3: \quad 8$ & 12: & +1 \\
\hline $4 / 3: 6$ & 8: & -15 & $4 / 3: 10$ & 13: & -4 \\
\hline & & & $4 / 3: 13$ & 16: & +7 \\
\hline Pipe 2 & & & 4/3: 13 & 17: & +18 \\
\hline $2 / 1: \quad 0$ & 9: & +5 & $4 / 3: 14$ & 18: & -3 \\
\hline 2/1: 2 & 11: & +4 & & & \\
\hline $3 / 2: \quad 3$ & 9: & +15 & Pipe & 1 Pipe & \\
\hline $3 / 2: 4$ & 10: & +11 & 1/1: 0 & 1: & +10 \\
\hline $3 / 2: 6$ & 11: & -11 & $1 / 1: \quad 1$ & 2: & +8 \\
\hline 4/3: 0 & 3: & -9 & 1/1: 3 & 4: & +11 \\
\hline $4 / 3: \quad 1$ & 5: & -2 & 1/1: 4 & 5: & +18 \\
\hline $4 / 3: \quad 2$ & 6: & +16 & 1/1: 7 & 9: & +16 \\
\hline 4/3: 4 & 8: & +18 & $2 / 1: 7$ & 0 : & -11 \\
\hline $4 / 3: 6$ & 10: & +1 & $2 / 1: 8$ & 1: & +3 \\
\hline & & & $2 / 1: \quad 1$ & 11: & -3 \\
\hline Pipe 3 & & & 2/1: 10 & 4: & -17 \\
\hline $2 / 1: \quad 0$ & 12: & +8 & $3 / 2: \quad 4$ & 0: & -14 \\
\hline $2 / 1: \quad 2$ & 13: & +19 & $3 / 2: 6$ & 1: & +18 \\
\hline $3 / 2: \quad 2$ & 8: & -8 & $3 / 2: \quad 1$ & 7: & +19 \\
\hline $3 / 2: 3$ & 10: & -10 & $3 / 2: \quad 2$ & 8: & -7 \\
\hline $3 / 2: 4$ & 11: & -11 & $3 / 2: \quad 7$ & 3: & -2 \\
\hline $3 / 2: \quad 5$ & 12: & -19 & $3 / 2: 8$ & 5: & +4 \\
\hline $4 / 3: \quad 1$ & 5: & -19 & $4 / 3: \quad 0$ & 5: & +9 \\
\hline $4 / 3: 3$ & 8: & -4 & $4 / 3: 4$ & 1: & +17 \\
\hline $4 / 3: 4$ & 9: & -1 & $4 / 3: \quad 1$ & 6: & +8 \\
\hline $4 / 3: 5$ & 10: & +15 & $4 / 3: 4$ & 9: & +20 \\
\hline $4 / 3: 6$ & 11: & +20 & & & \\
\hline $4 / 3: 7$ & 12: & -16 & Pipe 1 & 1 Pipe & \\
\hline & & & 1/1: 1 & 3: & +5 \\
\hline Pipe 4 & & & 1/1: 2 & 4: & +11 \\
\hline 1/1: 16 & 17: & +11 & 1/1: 3 & 6: & +11 \\
\hline $2 / 1: 3$ & 13: & -15 & $1 / 1: 4$ & 7: & +0 \\
\hline $2 / 1: 5$ & 14: & -9 & $1 / 1: 5$ & 8: & +20 \\
\hline $2 / 1: 8$ & 16: & +13 & 1/1: 6 & 9: & +4 \\
\hline $2 / 1: 10$ & 18: & -2 & 1/1: 7 & 11: & +11 \\
\hline $3 / 2: \quad 2$ & 9: & -2 & 2/1: 7 & 0 : & -18 \\
\hline $3 / 2: \quad 3$ & 10: & -11 & $2 / 1: 8$ & $2:$ & -13 \\
\hline $3 / 2: 6$ & $12:$ & -12 & $2 / 1: \quad 1$ & 13: & -9 \\
\hline $3 / 2: 8$ & 13: & +7 & 2/1: 10 & 6: & -16 \\
\hline $3 / 2: 10$ & 14: & +2 & $3 / 2: \quad 5$ & 1: & +10 \\
\hline $3 / 2: 12$ & 16: & +13 & $3 / 2: \quad 6$ & $2:$ & +2 \\
\hline $3 / 2: 13$ & 18: & +2 & $3 / 2: \quad 1$ & 10: & -5 \\
\hline 4/3: 0 & 5: & +9 & $3 / 2: \quad 3$ & $12:$ & -1 \\
\hline
\end{tabular}

$\begin{array}{lrrr}\text { 3/2: } & 8 & 7: & -14 \\ \text { 3/2: } & 9 & 19: & -4 \\ \text { 4/3: } & 4 & 2: & +1 \\ \text { 4/3: } & 1 & 8: & -16 \\ \text { 4/3: } & 6 & 4: & -12 \\ \text { 4/3: } & 7 & 7: & +4 \\ \text { 4/3: } & 4 & 11: & -7 \\ \text { 4/3: } & 8 & 9: & -11 \\ \text { 4/3: } & 7 & 14: & +18 \\ \text { 4/3: } & 10 & 12: & -4\end{array}$

Pipe 2 Pipe 3

1/1: $1 \quad 0:+10$

1/1: $2 \quad 2:+13$

1/1: $4 \quad 4: \quad+5$

1/1: $5 \quad 5:+19$

1/1: 8 9: +15

1/1: 9 10: +4

1/1: 10 11: +17

2/1: 0 10: +2

2/1: 11 12: $\quad-2$

2/1: $11 \quad 2: \quad-8$

3/2: $0 \quad 5:-13$

3/2: $1 \quad 7:+14$

3/2: $2 \quad 8: \quad+5$

3/2: 7 2: +14

3/2: 3 10: +11

$3 / 2: \quad 9 \quad 3:-6$

3/2: 4 11: -6

3/2: $10 \quad 4: \quad+6$

3/2: 5 12: 0

3/2: 6 13: +16

3/2: 7 14: +16

4/3: $\quad 0 \quad 3:+12$

4/3: 5 0: $\quad+8$

4/3: 1 5: +18

4/3: $6 \quad 2: \quad+3$

4/3: 3 8: +17

4/3: $7 \quad 3:+18$

4/3: 4 9: +4

4/3: 8 4: +13

4/3: 9 5: +19

4/3: 6 11: -16

4/3: $11 \quad 8:-1$

4/3: 7 13: +5
Pipe 3 Pipe 4

1/1: 2 3: +1

1/1: 3 5: +4

1/1: 4 6: +6

1/1: 5 7: +1

1/1: $6 \quad 8:+12$

1/1: 7 9: +1

1/1: 8 10: +2

1/1: $11 \quad 12: \quad+7$

2/1: $10 \quad 0: \quad-5$

2/1: $12 \quad 2:-18$

2/1: 2 13: -14

2/1: $13 \quad 3:+18$

2/1: 3 14: $\quad-5$

2/1: 8 18: $\quad-4$

3/2: $5 \quad 0:-20$

3/2: $6 \quad 1:+18$

3/2: $7 \quad 2: \quad-2$

3/2: 2 10: $\quad-10$

$3 / 2: \quad 8 \quad 3: \quad-8$

$3 / 2: \quad 9 \quad 4: \quad-10$

3/2: $10 \quad 5:-15$

3/2: $11 \quad 6: \quad-5$

3/2: $4 \quad 12: \quad-18$

3/2: 12 7: -18

3/2: 6 13: +19

$3 / 2: \quad 8 \quad 14: \quad-1$

3/2: 11 16: +6

3/2: $11 \quad 17:+17$

3/2: 13 19: +15

4/3: $\quad 3$ 0: $\quad+5$

4/3: $5 \quad 2: \quad+2$

4/3: $\quad 1 \quad 7: \quad-20$

4/3: 7 4: -15

4/3: 3 10: -6

4/3: 8 5: $\quad-8$

4/3: 9 6: +4

4/3: $10 \quad 7:+16$

4/3: 5 11: $\quad-8$

4/3: 6 12: +13

4/3: $11 \quad 8: \quad+8$

4/3: $12 \quad 9:-15$

4/3: 8 13: -6

4/3: 10 14: +5

4/3: 13 17: -15

4/3: 14 19: +4 


\section{BIBLIOGRAPHY}

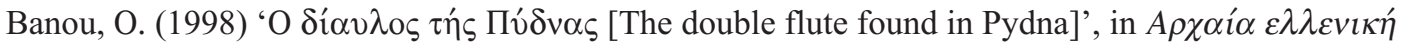

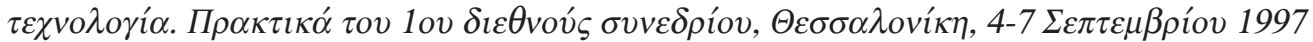
(Thessalonike) 519-24

Barker, A. (1995) 'Heterophonia and poikilia: accompaniments to Greek melody', in B. Gentili and F. Perusino (eds), Mousike. Metrica ritmica e musica greca (Pisa and Roma) 41-60

- (2002) Euterpe. Ricerche sulla musica greca e romana (Pisa)

Becker, H. (1966) Zur Entwicklungsgeschichte der antiken und mittelalterlichen Rohrblattinstrumente (Hamburg)

Behn, F. (1954) Musikleben im Altertum und frühen Mittelalter (Stuttgart)

Bélis, A. (2004) 'Un papyrus musical inédit au Louvre', Comptes rendus de l'académie des inscriptions et belles-lettres 2004.3, 1305-29

Benade, A.H. (1960) 'On the mathematical theory of woodwind finger holes', Journal of the Acoustical Society of America 32.12, 1591-1608

Bodley, N.B. (1946) 'The auloi of Meroë', American Journal of Archaeology 50, 217-40; pls 1-8

Byrne, M. (2000) 'Understanding the aulos', in E. Hickmann, I. Laufs and R. Eichmann (eds), Studien zur Musikarchäologie 2, Orient-Archäologie 7, 279-85

- (2002) 'Understanding the aulos II. Extended pipes and drone', in E. Hickmann, A.D. Kilmer and R. Eichmann (eds), Studien zur Musikarchäologie 3, Orient-Archäologie 10, 367-73

Curtis, J. (1914) 'The double flutes', JHS 34, 89-105

$D A G M=$ E. Pöhlmann and M.L. West, Documents of Ancient Greek Music (Oxford 2001)

Franklin, J.C. (2002) 'Diatonic music in Greece: a reassessment of its antiquity', Mnemosyne 55, 669-702

Gevaert, F.A. (1881) Histoire et théorie de la musique de l'antiquité 2 (Gent) (reprinted Hildesheim 1965)

Hagel, S. (2000) Modulation in altgriechischer Musik (Frankfurt am Main)

- (2004) 'Calculating auloi - the Louvre aulos scale', in E. Hickmann and R. Eichmann (eds), Studien zur Musikarchäologie 4, Orient-Archäologie 15, 373-90

- (2005a) 'Twenty-four in auloi. Aristotle, Met. 1093b, the harmony of the spheres, and the formation of the Perfect System', in S. Hagel and C. Harrauer (eds), Ancient Greek Music in Performance (Vienna) 51-91

- (2005b) 'Is nìd qabli Dorian? Tuning and modality in Greek and Hurrian music', Baghdader Mitteilungen 36, 287-348

- (2006) 'The context of tunings: thirds and septimal intervals in ancient Greek music', in E. Hickmann, A.A. Both and R. Eichmann (eds), Studien zur Musikarchäologie 5. Orient-Archäologie 20, 281-304

Howard, A.A. (1893) 'The av̉ 'ós or tibia', Harvard Studies 4, 1-63

Kilmer, A.D. (2001) 'Mesopotamia', in The New Grove Dictionary of Music and Musicians 16 (2nd edn, London) 480-7

Landels, J.G. (1981) 'The reconstruction of ancient Greek auloi', World Archaeology 12, 298-302

- (1999) Music in Ancient Greece and Rome (London and New York)

Letters, R.J. (1969) 'The scales of some surviving auloi', $C Q$ 19, 266-8

Litvinsky, B.A. (1999) 'греческие флейты (авлосы) в глубинной азии. Greek flutes (auloi) in Central Asia', in Monumentum Marcelle Duchesne-Guillemin, Acta Iranica 3.19, 517-43

Masaraki, D.W. (1974) 'Ein Aulos der Sammlung Karapanos', Mitteilungen des Deutschen Archäologischen Instituts (Athen. Abt.) 89, 105-21

Olsen, P.R. (1967) 'An aulos in the Danish National Museum', Dansk Aarbog for Musikforskning 1966$67,1-9$

Psaroudakês, S. (2002) 'The aulos of Argithea', in E. Hickmann, A.D. Kilmer and R. Eichmann (eds), Studien zur Musikarchäologie 3, Orient-Archäologie 10, 335-66

Schlesinger, K. (1939) The Greek aulos (London) (reprinted Groningen 1970)

Southgate, T.L. (1915) 'Ancient flutes from Egypt', JHS 35, 12-21

West, M.L. (1992) Ancient Greek Music (Oxford)

- (1994) 'The Babylonian musical notation and the Hurrian melodic texts', Music and Letters 75, 161-79

Wilson, P. (1999) 'The aulos in Athens', in S. Goldhill and R. Osborne (eds), Performance Culture and Athenian democracy (Cambridge) 58-95

Winnington-Ingram, R.P. (1936) Mode in Ancient Greek Music (Cambridge)

Yuan, J. (2005) 'Fragment with musical notation', Oxyrhynchus Papyri 69, 4710, pl. 1 


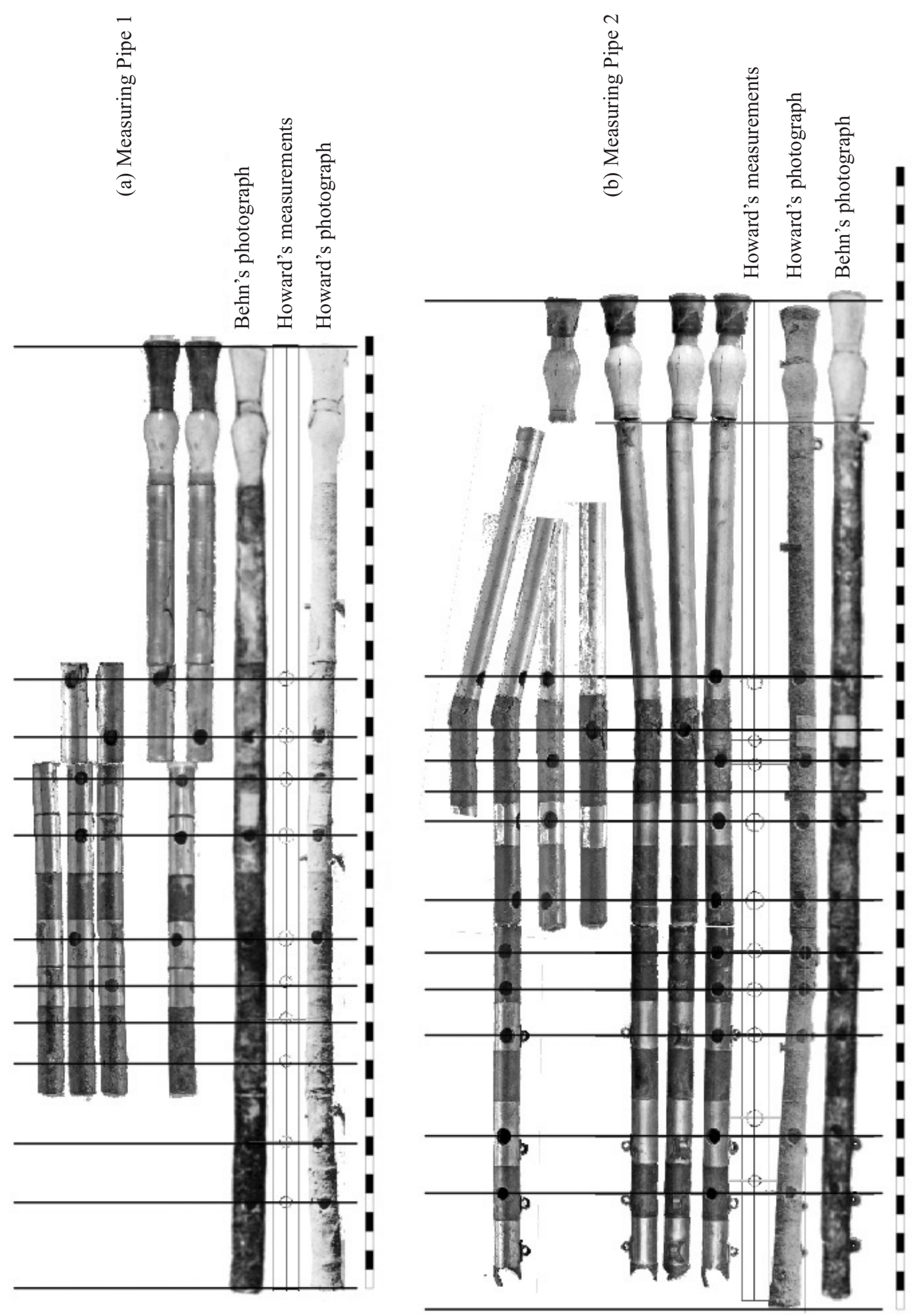



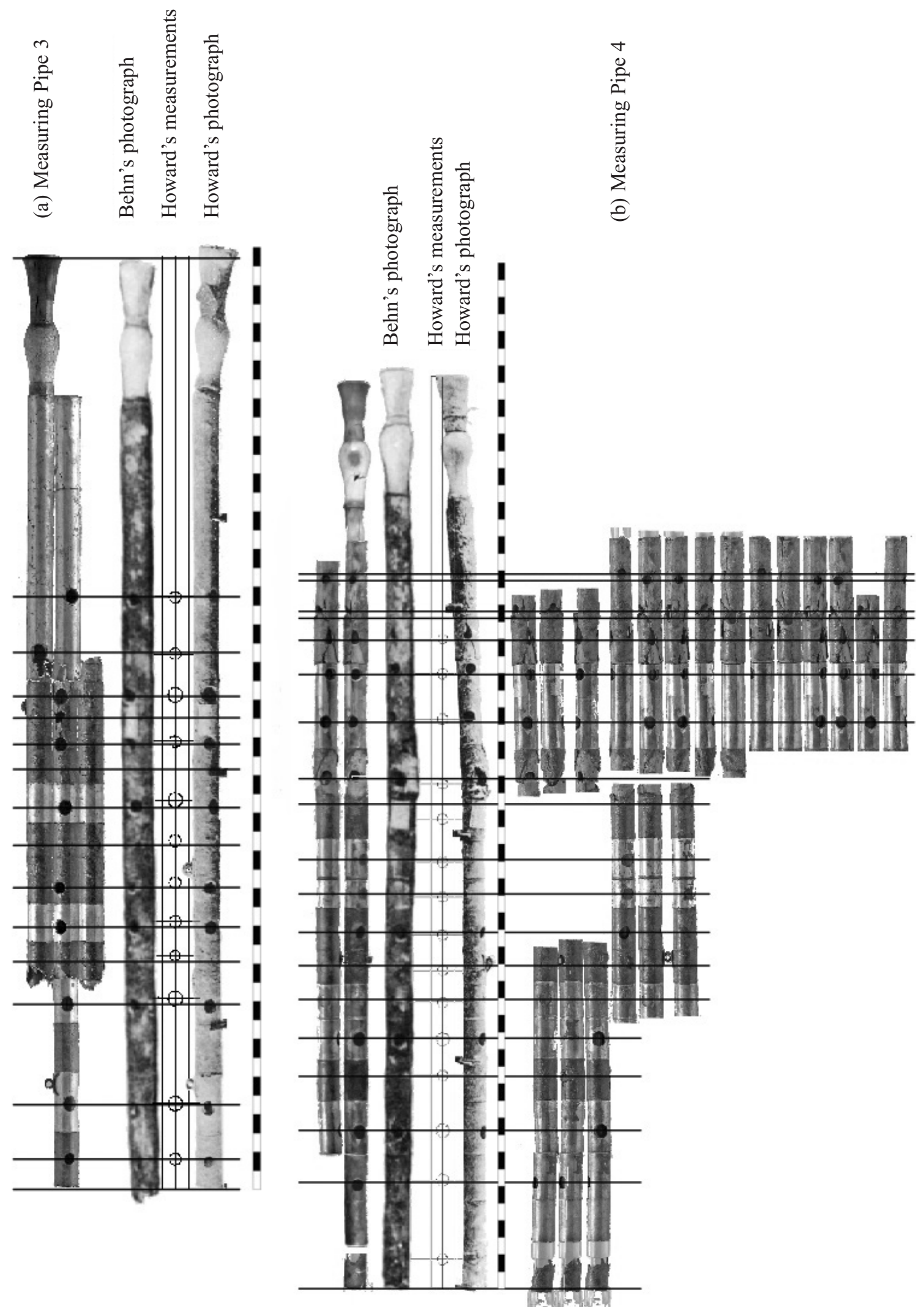


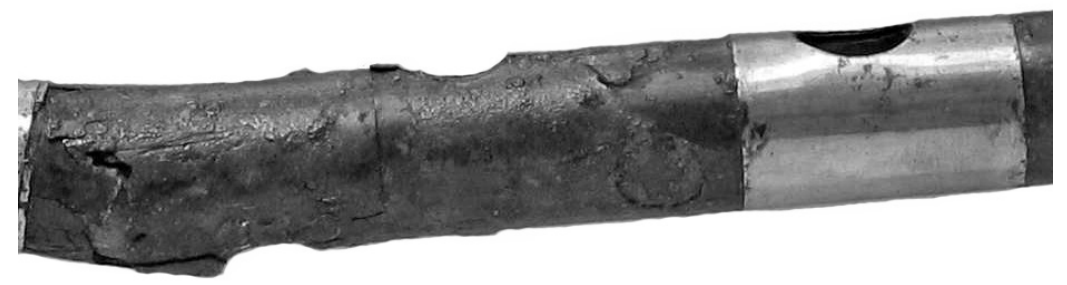

(a) Traces of finger hole no. 8 on Pipe 2

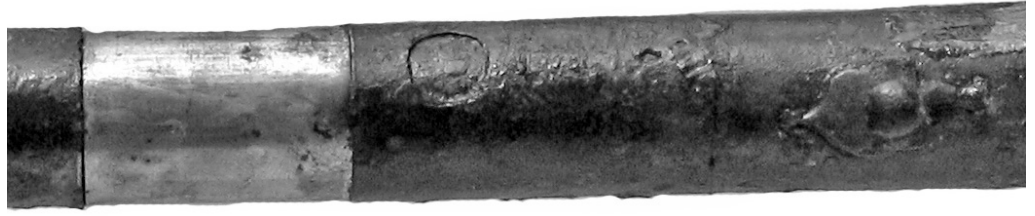

(b) Finger hole no. 9 on Pipe 3

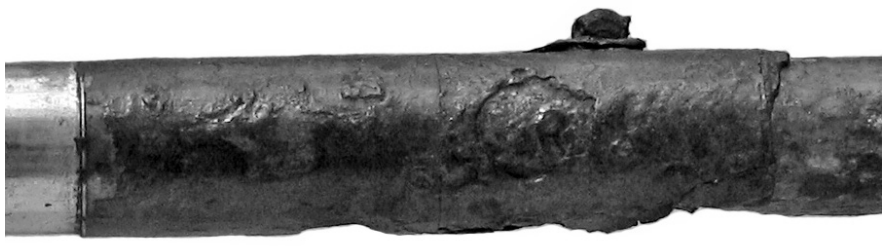

(c) Traces of finger hole no. 11 on Pipe 3

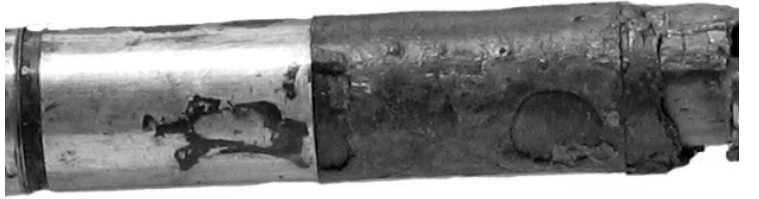

(d) Finger hole no. 11

on Pipe 4
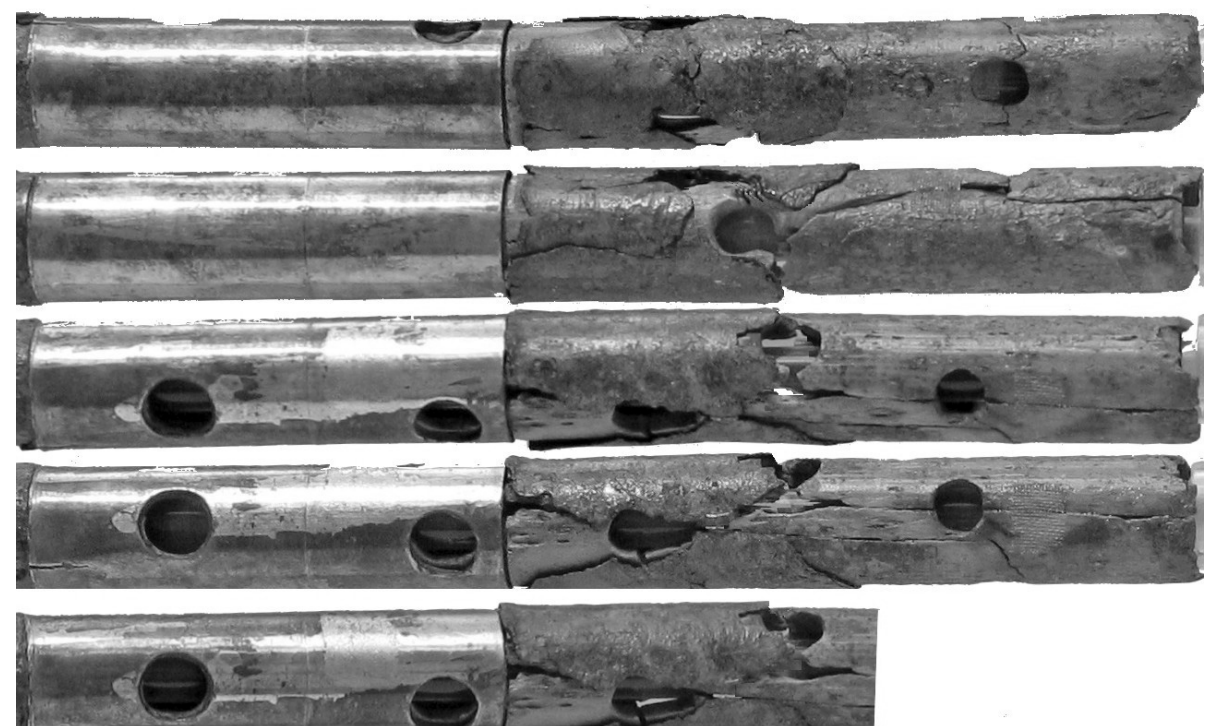

(e) Finger holes nos. 13-19

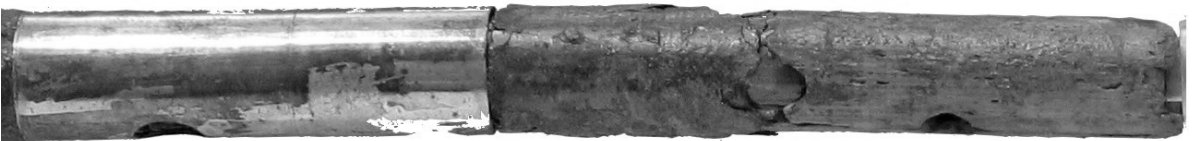

on Pipe 4 